Special issue article

Relationship of physical therapy inpatient rehabilitation interventions and patient characteristics to outcomes following spinal cord injury: The SCIRehab project

\title{
Laura Teeter ${ }^{1}$, Julie Gassaway², Sally Taylor 3 , Jacqueline LaBarbera4, Shari McDowell ${ }^{1}$, Deborah Backus ${ }^{1}$, Jeanne M. Zanca5, Audrey Natale ${ }^{6}$, Jordan Cabrera5, Randall J. Smout ${ }^{2}$, Scott E. D. Kreider ${ }^{6}$, Gale Whiteneck ${ }^{6}$
}

${ }^{1}$ Shepherd Center, Atlanta, Georgia, GA, USA, ${ }^{2}$ Institute for Clinical Outcomes Research, Salt Lake City, UT, USA, ${ }^{3}$ Rehabilitation Institute of Chicago, Chicago, IL, USA, ${ }^{4}$ Carolinas Rehabilitation, Charlotte, NC, USA, ${ }^{5}$ Mount Sinai Medical Center, New York, NY, USA, ${ }^{6}$ Craig Hospital, Englewood, CO, USA

Background/objective: Examine associations of type and quantity of physical therapy (PT) interventions delivered during inpatient spinal cord injury $(\mathrm{SCl})$ rehabilitation and patient characteristics with outcomes at the time of discharge and at 1 year post-injury.

Methods: Physical therapists delivering routine care documented details of PT interventions provided. Regression modeling was used to predict outcomes at discharge and 1 year post-injury for a $75 \%$ subset; models were validated with the remaining $25 \%$. Injury subgroups also were examined: motor complete low tetraplegia, motor complete paraplegia, and American Spinal Injury Association (ASIA) Impairment Scale (AIS) D motor incomplete tetra-/paraplegia.

Results: PT treatment variables explain more variation in three functionally homogeneous subgroups than in the total sample. Among patients with motor complete low tetraplegia, higher scores for the transfer component of the discharge motor Functional Independence Measure () are strongly associated with more time spent working on manual wheelchair skills. Being male is the most predictive variable for the motor FIM score at discharge for patients with motor complete paraplegia. Admission ASIA lower extremity motor score (LEMS) and change in LEMS were the factors most predictive for having the primary locomotion mode of "walk" or "both (walk and wheelchair)" on the discharge motor FIM for patients with AIS D injuries.

Conclusion: Injury classification influences type and quantity of PT interventions during inpatient $\mathrm{SCl}$ rehabilitation and is a strong predictor of outcomes at discharge and 1 year post-injury. The impact of PT treatment increases when patient groupings become more homogeneous and outcomes become specific to the groupings.

Note: This is the second of nine articles in the SCIRehab series.

Keywords: Spinal cord injuries, Rehabilitation, Physical therapy, Paraplegia, Tetraplegia, Participation, Quality of life, Employment, Functional outcome practicebased evidence, $\mathrm{SCl}$ model systems

\section{Introduction}

Spinal cord injury (SCI) is a complex condition that results in multiple impairments, most notably, varying degrees of motor and sensory loss. Injuries are classified according to the International Standards of Neurological Classification for SCI (ISNCSCI) ${ }^{1}$ based

Correspondence to: Gale Whiteneck, Craig Hospital, 3425 S. Clarkson St, Englewood, CO 80113. Email: gale@craig-hospital.org on the neurological level of injury (the lowest level of the spinal cord with normal sensory and motor function on both sides of the body) and the ASIA Impairment Scale (AIS) score, which describes the extent of motor and/or sensory function that remains below the neurological level. Injuries classified as AIS A or B are considered "motor complete" because there is no preservation of motor function below the level of injury. Persons with AIS $\mathrm{C}$ injuries have muscle strength 
grades of less than 3 out of 5 in at least half of the key muscles below their level of injury, while individuals with AIS D injuries have strength grades of 3 or higher in these muscles. SCI-related impairments contribute to functional limitations, such as difficulty in performing activities such as bed mobility (turning, rolling, sitting up in bed), transfers (to and from bed, toilet, tub) and ambulation.

Physical therapy (PT) is an essential component of comprehensive rehabilitation following traumatic SCI. PT interventions are designed to facilitate recovery of, or compensation for, impairments and functional limitations. PT interventions also aim to prevent secondary complications of SCI, including respiratory infections $\mathrm{s}^{2,3}$ and skin breakdown, ${ }^{4,5}$ by increasing patient and caregiver knowledge of the injury, training caregivers on how to provide physical assistance when necessary and promoting lifelong patient health and wellness. PT interventions seek to promote participation and enable return to pre-morbid societal roles, enhancing overall well-being following SCI.

Much research has related patient demographics and injury characteristics to outcomes following SCI. In patients with SCI, the strongest predictors of functional independence outcomes are the level and completeness of injury. ${ }^{6,7}$ Other patient characteristics have been associated with outcomes related to function (age ${ }^{8}$ and body mass index $\left(\mathrm{BMI}^{9}\right)$ ), residential location (age, race, payer source, marital status, education level, employment status at injury, admission Functional Independence Measure $\left(\mathrm{FIM}^{\mathbb{B}}\right)$ scores, and ventilator use), ${ }^{10,11}$ societal participation (gender and education level), ${ }^{12,13}$ quality of life (ventilator use), ${ }^{14}$ utilization, including rehospitalization (age, gender, BMI, comorbidities, and level of injury) ${ }^{15,16}$ and secondary complications, such as pressure ulcer development (marital status, level of injury, and AIS classification ${ }^{5,17}$ ) and depression (ventilator use).${ }^{14}$ Some research has related patient characteristics, including overall severity of illness, to treatment differences, ${ }^{18,19}$ but there is a lack of research examining associations between treatment differences and outcomes, controlling for patient characteristics. $^{20-22}$

Very little is known about which rehabilitation intervention types and dosages produce the best outcomes for patients with SCI. In a study that explored the relationship between therapy intensity and functional gains during inpatient SCI rehabilitation, subgroup analyses based on admission Functional Independence Measure (FIM) scores were utilized. ${ }^{23}$ Initial functional ability, as well as therapy intensity, was associated with FIM gains during rehabilitation. The incorporation of additional demographic and injury characteristics (such as level of injury, age and severity of complications, and comorbidities) is warranted to explore the relationship of these characteristics and PT interventions with functional outcomes. In addition, further subgroup analysis is necessary to predict improvement in specific FIM items that would be expected to change for these patients. ${ }^{23}$

Recently, efforts have been made to develop methods of classifying rehabilitation interventions, ${ }^{21,22,24}$ to guide decision-making about the most appropriate type and dosage of intervention and optimize outcomes for patients with SCI. Developing taxonomies for each rehabilitation discipline, including PT, was the first stage of the SCIRehab project, a multi-center investigation based in the USA. ${ }^{24,25}$ The PT taxonomy was the basis of the electronic documentation in which clinicians recorded the content of each PT session for patients enrolled in the study. It was comprised of 21 PT activities delivered during individual or group sessions, including classes, clinics, and conferences involving physical therapists. ${ }^{24}$ In the second stage of the SCIRehab project, analyses were conducted to better understand the type and amount of interventions that are provided in inpatient rehabilitation. TaylorSchroeder et $a l .{ }^{26}$ reported a significant difference in time spent in each PT activity among four neurological groups (C1-4 AIS ABC, C5-8 AIS ABC, Para AIS $\mathrm{ABC}$, and AIS D). Range of motion (ROM)/stretching, strengthening, and transfer training were the top three PT activities in each group except the group of those with injuries classified as AIS D who were more likely to work on gait training, strengthening, and balance exercises.

The findings of Taylor-Schroeder et al. ${ }^{26}$ suggest that physical therapists consider patient demographic and injury characteristics in the selection of interventions in order to reach goals agreed upon by the patients and therapists. There is, however, a paucity of evidence regarding what specific PT interventions are most important to functionally homogeneous subgroups of patients in order to optimize outcomes. The large sample size in the SCIRehab study and the use of an all-inclusive taxonomy of PT interventions provide a unique opportunity for a comprehensive examination of factors associated with functional and quality-of-life outcomes for people with SCI.

The first article in this current series of papers reported that time spent in PT, as quantified by the total hours of therapy over the rehabilitation stay, is significantly associated with several outcomes. These include function (higher FIM motor scores at the time 
of rehabilitation discharge and at 1 year post-injury), participation (higher scores on the Craig Handicap Assessment and Reporting Technique (CHART) dimensions of Physical Independence, Social Integration and Mobility), quality of life (Diener Satisfaction With Life Scale), utilization (rehospitalization) and development of pressure ulcers after rehabilitation discharge. ${ }^{27}$

This current paper has three purposes. The first is to examine the association between patient characteristic (demographic and injury-related) and functional, residential, participation, quality of life, utilization, and secondary complication outcomes achieved at discharge from inpatient rehabilitation and at 1 year post-injury. The second purpose is to examine the added contribution of type and quantity of PT interventions to the variance in outcomes explained by patient characteristics. The third purpose is to explore how PT interventions relate to specific functional outcomes in three homogeneous injury subgroups: motor complete low tetraplegia (C5-C8), motor complete paraplegia (T1-T9) and AIS D (all levels of injury). It is hypothesized that patient characteristics and type and quantity of PT interventions will be predictors of each outcome at discharge and 1 year post-injury.

\section{Methods}

The practice-based evidence (PBE) research methodology used in the SCIRehab study has been described previously and is summarized in the first article of this SCIRehab series. ${ }^{19,25,28,29}$

\section{Study sample and facilities}

The SCIRehab project enrolled 1376 patients who were 12 years of age or older, gave (or whose parent/guardian gave) informed consent and were admitted to one of six facilities' SCI units (Craig Hospital, Englewood, CO, USA; Shepherd Center, Atlanta, GA, USA; Rehabilitation Institute of Chicago, Chicago, IL, USA; Carolinas Rehabilitation, Charlotte, NC, USA; The Mount Sinai Medical Center, New York, NY, USA; or National Rehabilitation Hospital, Washington, DC, USA) for initial rehabilitation following traumatic SCI between the fall of 2007 and December 31, 2009. Results reported here are for an "analytic subset" of 1032 (a randomly selected $75 \%$ of the full dataset of 1376 patients); the regression models were tested using the validation subset, which contained the remaining $25 \%$ of patients.

\section{Patient data}

Patient demographic and injury data were abstracted either from the patient medical record, as part of the
National Institute on Disability and Rehabilitation Research (NIDRR) SCI Model Systems Form I, which contains information concerning injury through community discharge, or from a database designed specifically for the SCIRehab study. The ISNCSCI and AIS $^{1}$ were used to describe the neurological level and completeness of injury; the FIM served to describe a patient's functional independence in motor and cognitive tasks at rehabilitation admission ${ }^{30}$ and the Comprehensive Severity Index $\left(\mathrm{CSI}^{\circledR}\right)$ provided a disease-specific measure of illness severity. ${ }^{31-33}$ Weight was categorized as not obese $(\mathrm{BMI}<30)$ or obese $(B M I \geq 30)$. Table 1 provides a description of the sample in terms of all patient characteristics.

\section{PT treatment data}

Physical therapists and physical therapist assistants (PTAs) documented detailed information about treatment provided during each PT session, beyond what was documented in traditional medical record documentation, by entering data into handheld personal digital assistants (PDAs) after each encounter with a patient. ${ }^{24,25}$ Therapists documented the session date/ time, the number of minutes spent on 21 different intervention activities performed in the session, activityspecific details and the extent of patient participation in the session. The total time (hours) in specific PT activities over the rehabilitation stay is reported in Table 2. The patient's level of participation was quantified using the Pittsburgh Rehabilitation Participation Scale $(1=$ none and $6=$ excellent $)$, which was designed to measure patient participation during therapy by defining a cluster of observable behaviors that serve as a surrogate for patient motivation. ${ }^{34}$ The mean participation score for each patient was calculated by averaging scores across all PT sessions.

\section{Clinician experience}

Each physical therapist and PTA who provided treatment information to the SCIRehab database completed a clinician profile, which provided information about years of experience working in SCI rehabilitation. The average experience of those treating each patient was calculated, weighting the experience of each therapist by the number of hours of treatment he or she provided.

\section{Outcome data}

Outcome measures were obtained at the time of rehabilitation discharge and at 1 year post-injury. These outcomes and the processes of obtaining them are described in detail in the first article in this SCIRehab series. ${ }^{27}$ Briefly, the study utilized standardized information collected by the NIDRR SCI Model Systems; 
Table 1 Patient and injury characteristics, for full sample and three subgroups

\begin{tabular}{|c|c|c|c|c|}
\hline & $\begin{array}{c}\text { C5-8 } \\
\text { AIS A, B } \\
n=78\end{array}$ & $\begin{array}{c}\text { T1-9 } \\
\text { AIS A, B } \\
n=158\end{array}$ & $\begin{array}{c}\text { AIS D } \\
n=158\end{array}$ & $\begin{array}{l}\text { SCIRehab study sample } \\
\qquad n=1032\end{array}$ \\
\hline Age at injury, mean (SD) & $31.7(15.1)$ & $31.5(13.0)$ & $47.8(18.1)$ & $37.7(16.7)$ \\
\hline Gender, \% male & 81 & 79 & 84 & 81 \\
\hline \multicolumn{5}{|l|}{ Race/ethnicity \% } \\
\hline White & 77 & 72 & 63 & 71 \\
\hline Black & 17 & 22 & 27 & 22 \\
\hline Hispanic & 1 & 3 & 2 & 3 \\
\hline Other & 5 & 3 & 8 & 5 \\
\hline Primary language, \% English primary language & 95 & 95 & 95 & 94 \\
\hline \multicolumn{5}{|l|}{ Payer \% } \\
\hline Medicare & 4 & 3 & 17 & 7 \\
\hline Medicaid & 20 & 24 & 11 & 18 \\
\hline Private insurance/payer & 73 & 63 & 63 & 64 \\
\hline Worker's compensation & 3 & 10 & 9 & 11 \\
\hline Marital Status at injury, \% married & 23 & 32 & 42 & 38 \\
\hline \multicolumn{5}{|l|}{ Education \% } \\
\hline Less than high school diploma & 27 & 20 & 15 & 20 \\
\hline High school diploma or GED & 45 & 56 & 48 & 51 \\
\hline More than high school diploma & 26 & 20 & 28 & 25 \\
\hline Other/unknown & 3 & 4 & 9 & 4 \\
\hline \multicolumn{5}{|l|}{ Employment status before injury \% } \\
\hline Working & 63 & 73 & 58 & 66 \\
\hline Student & 19 & 15 & 12 & 15 \\
\hline Retired & 1 & 1 & 18 & 8 \\
\hline Unemployed/other & 17 & 11 & 12 & 11 \\
\hline \multicolumn{5}{|l|}{ Injury etiology \% } \\
\hline Vehicular & 49 & 62 & 44 & 49 \\
\hline Violence & 10 & 15 & 5 & 11 \\
\hline Sports & 26 & 2 & 8 & 11 \\
\hline Fall or falling object & 15 & 18 & 37 & 25 \\
\hline Medical/surgical or other & 0 & 3 & 6 & 4 \\
\hline Injury work related? \% no & 97 & 87 & 89 & 86 \\
\hline Body mass index at Admission, \% Less than 30 & 90 & 78 & 79 & 82 \\
\hline Admission Motor FIM, mean (SD) - Rasch transformed & $11.3(9.5)$ & $26.7(5.4)$ & $24.6(11.3)$ & $17.8(12.6)$ \\
\hline Admission cognitive FIM, mean (SD) - Rasch transformed & $71.2(15.4)$ & $76.6(16.0)$ & $79.7(17.6)$ & $73.6(18.1)$ \\
\hline Comprehensive Severity Index, mean (SD) & $40.6(24.9)$ & $35.5(23.2)$ & $21.5(17.5)$ & $40.0(31.6)$ \\
\hline Days from injury to rehabilitation, mean (SD) & $34.7(21.9)$ & $30.9(25.1)$ & $16.4(13.1)$ & $31.0(27.8)$ \\
\hline
\end{tabular}

information concerning injury through community discharge was contained on Form I and follow-up status at 1 year post-injury was included on Form II. ${ }^{35}$ An additional, project-specific interview was conducted to supplement the Form II. All interviewers were trained in the interview process and had experience conducting telephone interviews with patients with SCI, as described in the first article in this series. ${ }^{27}$ Outcomes at the time of rehabilitation discharge included discharge location (home or elsewhere) and the discharge FIM motor score. All FIM data were Rasch-transformed to convert discrete, ordinal FIM scores into scores on a continuous interval scale. ${ }^{27}$ Outcome measures at 1 year post-injury were derived primarily from Form II: FIM motor subscale score, four subscales from the CHART ${ }^{36-38}$ (Physical Independence, Social Integration, Occupation and Mobility), the Diener Satisfaction With Life Scale (SWLS), ${ }^{39}$ depression symptomatology as measured by the Patient Health
Questionnaire - brief (nine question) version (PHQ9), ${ }^{40}$ place of residence, work/school status, presence of a pressure ulcer, and rehospitalization during the period from rehabilitation discharge to 1 year postinjury. Rehospitalization information also was included on the project-specific interview, which was used to supplement Form II information when the rehospitalization data were missing.

\section{Identification of patient subgroups}

While strength or sensory improvements resulting in a change in AIS or level of injury could be related to therapeutic intervention, they could also be due to naturally occurring neurological improvement. ${ }^{41}$ To better understand the relationship that rehabilitation interventions have with achieving desired outcomes and to minimize the effect of natural recovery, subgroup analyses were conducted for those patients who were likely to have similar therapeutic needs and rehabilitation goals, 


\begin{tabular}{|c|c|c|c|c|}
\hline & $\begin{array}{c}\text { C5-8 } \\
\text { AIS A, B } \\
n=78\end{array}$ & $\begin{array}{c}\text { T1-9 } \\
\text { AIS A, B } \\
n=158\end{array}$ & $\begin{array}{c}\text { AIS D } \\
n=158\end{array}$ & $\begin{array}{l}\text { SCIRehab study sample } \\
\qquad n=1032\end{array}$ \\
\hline Length of rehabilitation stay - days, mean (SD) & $65.9(42.5)$ & $46.2(23.5)$ & $32.4(20.6)$ & $55.7(36.6)$ \\
\hline Clinician experience - PT, years, mean (SD) & $4.9(4.0)$ & $5.6(5.0)$ & $4.6(4.2)$ & $5.3(4.9)$ \\
\hline Patient participation score - PT, mean (SD) & $5.0(0.6)$ & $5.1(0.7)$ & $5.2(0.6)$ & $5.1(0.6)$ \\
\hline \multicolumn{5}{|l|}{ PT hours in specific treatments, mean (SD) } \\
\hline Airway/respiratory management & $0.4(1.1)$ & $0.1(0.4)$ & $0.0(0.3)$ & $0.2(1.0)$ \\
\hline Aquatic exercise & $0.8(2.3)$ & $0.6(1.8)$ & $0.9(2.5)$ & $1.0(2.5)$ \\
\hline Assessment & $1.6(1.4)$ & $1.5(1.5)$ & $2.2(1.8)$ & $2.1(2.0)$ \\
\hline Bed mobility & $4.5(3.9)$ & $2.8(2.2)$ & $0.7(1.1)$ & $2.4(2.7)$ \\
\hline Classes provided by PT & $0.4(0.8)$ & $0.3(0.7)$ & $0.2(0.5)$ & $0.4(0.9)$ \\
\hline Education & $2.0(2.2)$ & $1.3(1.4)$ & $0.4(0.9)$ & $1.5(1.9)$ \\
\hline Equipment evaluation, provision, and education & $2.8(2.6)$ & $2.4(2.7)$ & $0.8(1.5)$ & $2.6(3.1)$ \\
\hline Gait & $0.0(0.3)$ & $0.3(1.6)$ & $7.7(6.1)$ & $2.7(5.7)$ \\
\hline Interdisciplinary conferences (on patient's behalf) & $2.9(2.4)$ & $2.1(2.0)$ & $1.6(1.6)$ & $2.5(2.5)$ \\
\hline Musculoskeletal treatment modalities & $2.1(3.5)$ & $0.9(1.9)$ & $0.7(1.9)$ & $1.7(3.4)$ \\
\hline Pre-gait & $0.1(0.3)$ & $0.1(0.7)$ & $1.1(1.8)$ & $0.6(1.4)$ \\
\hline Skin management & $0.8(0.9)$ & $0.3(0.6)$ & $0.1(0.2)$ & $0.5(1.0)$ \\
\hline Therapeutic exercise - balance & $3.2(3.4)$ & $2.4(2.1)$ & $2.0(2.0)$ & $2.3(2.5)$ \\
\hline Therapeutic exercise- endurance & $3.6(6.8)$ & $2.3(4.1)$ & $1.9(3.8)$ & $2.9(5.5)$ \\
\hline Therapeutic exercise - ROM/Stretching & $9.9(7.7)$ & $6.1(4.3)$ & $2.2(3.3)$ & $7.9(8.1)$ \\
\hline Therapeutic exercise - strengthening & $11.1(10.1)$ & $8.1(8.5)$ & $9.5(8.1)$ & $10.5(9.9)$ \\
\hline Transfers & $8.5(4.8)$ & $8.7(4.5)$ & $2.7(3.1)$ & $7.0(5.1)$ \\
\hline Upright activities & $2.3(2.6)$ & $1.4(1.8)$ & $0.6(1.2)$ & $2.0(2.4)$ \\
\hline Wheelchair mobility - manual & $3.7(4.4)$ & $8.0(7.4)$ & $1.1(2.0)$ & $4.2(5.9)$ \\
\hline Wheelchair mobility - power & $2.5(3.3)$ & $0.3(0.8)$ & $0.4(1.1)$ & $1.4(2.5)$ \\
\hline Wound care & $1.3(5.2)$ & $0.2(1.4)$ & $0.2(1.5)$ & $0.2(2.1)$ \\
\hline
\end{tabular}

based on functional expectations and homogeneous injury classification.

The first subgroup of 78 cases included patients with motor complete (AIS A or B) lower cervical (C5-C8) SCI. Since a change in one or two motor levels within this cervical injury group can result in a large functional change in mobility activities, such as transfers, inclusion in this group was restricted to patient who did not change neurological level of injury between admission and discharge (e.g. C5 did not change to $\mathrm{C} 6,7$ or 8). The outcome of interest for this subgroup was the transfer component of the FIM motor score at discharge and at 1 year post-injury. This outcome was chosen since these patients have enough preservation of upper extremity strength to have functional goals for transferring between surfaces and the transfer component of the motor FIM provides information regarding the level of assistance required for three types of transfers (bed, chair, wheelchair; toilet; and tub/shower).

The second subgroup included 158 patients with injuries at thoracic levels 1-9 (T1-9) that were motor complete (AIS A or B) at both admission and discharge. Patients who changed neurological injury levels by discharge were included in this subgroup, as long as they remained within the T1-9 levels, as all would be expected to have similar functional expectations given full upper extremity function, but not full innervation of trunk musculature. ${ }^{6}$ Patients with motor complete injuries at T10 and below were not included in this functionally homogeneous group, as their functional expectations can be quite different due to further innervation of the trunk and lower extremities. With the addition of various types of bracing, patients with injuries at or below T10 are more likely to have goals for ambulation. ${ }^{6}$ Forty-one patients with brachial plexus injuries and/or upper extremity fractures were also excluded from this group to ensure all cases had intact upper extremity musculoskeletal and peripheral nervous system function. The FIM motor score was chosen as the outcome of choice for this subgroup as patients with motor complete paraplegia are expected to live independently and therefore, should require little (if any) assistance with mobility skills (as measured by the motor FIM) at discharge and 1 year post-injury. 6

A third subgroup included 158 patients who were admitted and discharged with AIS D motor incomplete injuries. These patients, who would be expected to have motor and sensory improvements from admission to discharge, were grouped together to create a homogeneous subset of patients who were most likely to be walking at the time of discharge. ${ }^{42}$ The outcome chosen for this group was the primary mode of locomotion on the discharge motor FIM ("walk", "chair" or "both"). A mode of locomotion indictor of "walk" or "both" on the discharge motor FIM would show that a patient is 
ambulating (as opposed to using a wheelchair) at least half of the time at the end of inpatient rehabilitation and was considered a measure of achieving functional ambulation. The FIM mode of locomotion was therefore dichotomized to "walk" or "both" vs. "wheelchair" at rehabilitation discharge. Additional regression models predicted the motor FIM score at the time of discharge and at 1 year post-injury as a measure of overall independence with mobility skills.

\section{Data analysis: regression modeling}

Ordinary least squares stepwise regression modeling was used to predict outcomes at discharge and 1 year postinjury for the analytic subset ( $75 \%$ of the sample). Linear regression ${ }^{43}$ was used for outcomes that are continuous and logistic regression for dichotomized outcomes. ${ }^{44}$ Three blocks of independent variables were allowed to enter the stepwise regression models: (1) all patient demographic and injury characteristics described in Table 1, (2) treatment variables that included time spent in PT activities, patient participation, clinician experience, and rehabilitation length of stay (LOS) (Table 2) and (3) rehabilitation center (dummy variables). Patient variables that were applicable for less than 10 patients and PT activities in which fewer than 10 patients participated were excluded from corresponding models (see footnotes of Tables $7-10)$. For linear regressions, the adjusted $R^{2}$ reduces the unadjusted $R^{2}$ to take into account the number of predictors in the model. The adjusted $R^{2}$ value indicates the amount of variation explained in the outcome by the significant independent variables, and thus, the strength of the model. $R^{2}$ values range from 0 (no prediction) to 1 (perfect prediction); values that are closer to 1 indicate better models. For logistic regression, the maximum re-scaled $R^{2}$ (Max $R^{2}$ ), also known as the Nagelkerke pseudo $R^{2}$ or Cragg and Uhler's $R^{2}$, is reported as a measure of the strength of the model. ${ }^{45}$ This value is scaled the same as the $R^{2}(0-1)$ and reflects the relative strength of the predictive logistic model. In addition, for logistic regression, discrimination was assessed by using the area under the receiver operator characteristic curve ( $c$ statistic) to evaluate how well the model distinguished patients who did not achieve an outcome from patients who did. Values of $\mathrm{c}$ that are closer to 1 indicate better discrimination.

In each regression, the adjusted $R^{2}$ (linear regression) or the $c$ statistic and the Max $R^{2}$ (logistic regression) are reported first for the prediction of the outcome with only patient characteristics included as independent variables. Next, the same statistics are reported for the combination of treatment variables and patient characteristics. Finally, to determine the added impact of rehabilitation center effects, dummy variables indicating each patient's rehabilitation center were added to the model (in addition to the treatment and patient variables) and the adjusted $R^{2}$ or $c$ statistic/Max $R^{2}$ are reported. The change in the adjusted $R^{2}$ or c statistic/ Max $R^{2}$ as the treatment variables and then the center variables are added indicates the additional explanation contributed by these components. For all outcome models, parameter estimates (based on the regressions including patient/injury and treatment variables, but not center) are reported, indicating the direction and strength of the association between each independent variable and the outcome. In the linear regression models, semi-partial Omega $R^{2}$ s are reported, which indicate the proportion of the variance in the dependent variable that is associated uniquely with the predictor variable in question. In the logistic regressions, odds ratios (OR) are reported to indicate the magnitude of the association of the predictor variable with the outcome. An OR of 2 indicates that the outcome is twice as likely for each unit increase in the independent variable, and an OR of 0.5 indicates that the outcome is only half as likely. In all regression models, the $P$ value associated with each significant predictor also is reported.

\section{Data analysis: model validation}

Regression models involving the full dataset (not the subgroups) were validated, as described here. For continuous outcomes, the relative shrinkage of the original model $R^{2}$ that included all patient, treatment and center variables as the predictors was determined by comparing it to the $R^{2}$ for the same outcome using the $25 \%$ sample and only the significant variables from the original model ${ }^{46} \mathrm{~A}$ shrinkage (relative difference in $R^{2}$ ) of $<0.1$ was considered to indicate a wellvalidated model. Validation was considered to be moderate when the shrinkage was between 0.1 and 0.2 , and models were considered to be validated poorly if shrinkage was $>0.2$. For dichotomous outcomes, the Hosmer Lemeshow (HL) goodness of fit test $P$ value was calculated both for the original model and for its replication in the validation subgroup. Models validated well if the HL $P$ value was $>0.1$ for both, which indicates no lack of fit in either model. Models were considered to validate moderately well if the HL $P$ value was $0.05-0.1$ for one or both models, indicating some evidence of lack of fit, and to validate poorly if the HL $P$ value was $<0.05$ for one or both, which indicates a lack of fit in one or both of the models. 


\section{Table 3 Prediction of Motor FIM* at discharge and 1 year post-injury}

\begin{tabular}{|c|c|c|c|c|c|c|}
\hline $\begin{array}{l}\text { Outcome } \\
\text { Observations used }\end{array}$ & \multicolumn{3}{|c|}{ Motor FIM at discharge } & \multicolumn{3}{|c|}{ Motor FIM at 1 year } \\
\hline $\begin{array}{l}\text { Observations used } \\
\text { Step 1: Pt characteristics: adj. } R^{2} \\
\text { Step 2: Pt characteristics + treatments: adj. } R^{2} \\
\text { Step 3: Pt characteristics + treatments + center identity: adj. } R^{2}\end{array}$ & & $\begin{array}{l}1031 \\
0.65 \\
0.77 \\
0.78\end{array}$ & & & $\begin{array}{l}859 \\
0.51 \\
0.61 \\
0.62\end{array}$ & \\
\hline Independent variables** & Parameter estimate & $P$ value & Semi partial omega ${ }^{2}$ & Parameter estimate & $P$ value & Semi partial omega 2 \\
\hline Neurological group & - & $<0.001$ & 0.031 & - & $<0.001$ & 0.032 \\
\hline $\mathrm{C} 1-4 \mathrm{ABC}$ & -9.183 & $<0.001$ & - & -18.912 & $<0.001$ & - \\
\hline C5-8 ABC & -6.503 & $<0.001$ & - & -12.454 & $<0.001$ & - \\
\hline Para $A B C$ & -1.909 & 0.006 & - & -9.312 & $<0.001$ & - \\
\hline All Ds (reference) & 0.000 & - & - & 0.000 & - & - \\
\hline Admission FIM motor ${ }^{\star}$ & 0.375 & $<0.001$ & 0.051 & 0.570 & $<0.001$ & 0.033 \\
\hline \multicolumn{7}{|l|}{ Comprehensive Severity Index } \\
\hline Days from trauma to rehabilitation admission & -0.029 & $<0.001$ & 0.003 & -0.086 & $<0.001$ & 0.009 \\
\hline Age at injury & -0.056 & $<0.001$ & 0.004 & -0.238 & $<0.001$ & 0.017 \\
\hline Highest education achieved & & & & - & 0.010 & 0.003 \\
\hline High school & & & & 3.479 & 0.009 & - \\
\hline College & & & & 4.550 & 0.004 & - \\
\hline$<12$ Years/other/unknown (reference) & & & & 0.000 & - & - \\
\hline Injury is work related & 1.311 & 0.018 & 0.001 & & & \\
\hline $\mathrm{BMI} \geq 30$ & -1.781 & $<0.001$ & 0.003 & & & \\
\hline Primary payer & & & & - & 0.010 & 0.004 \\
\hline Medicare & & & & -0.997 & 0.673 & - \\
\hline Medicaid & & & & -3.712 & 0.007 & - \\
\hline Worker's compensation & & & & -4.206 & 0.014 & - \\
\hline Private insurance/pay (reference) & & & & 0.000 & - & - \\
\hline Patient participation score - PT & 1.917 & $<0.001$ & 0.007 & 4.739 & $<0.001$ & 0.012 \\
\hline \multicolumn{7}{|l|}{ PT hours of specific treatments: } \\
\hline Airway/respiratory management & -0.742 & $<0.001$ & 0.003 & -1.053 & 0.031 & 0.002 \\
\hline Aquatic exercises & 0.253 & 0.011 & 0.001 & & & \\
\hline Assessment & 0.665 & $<0.001$ & 0.005 & 1.323 & $<0.001$ & 0.007 \\
\hline Classes provided by PT & -0.913 & $<0.001$ & 0.003 & & & \\
\hline Equipment evaluation/provision/education & -0.211 & 0.015 & 0.001 & -0.827 & $<0.001$ & 0.006 \\
\hline Gait & 0.248 & $<0.001$ & 0.008 & 0.810 & $<0.001$ & 0.022 \\
\hline Musculoskeletal treatment modalities & -0.141 & 0.029 & 0.001 & & & \\
\hline Pre-gait & 0.642 & $<0.001$ & 0.004 & 1.595 & $<0.001$ & 0.007 \\
\hline Range of motion/stretching exercises & -0.077 & 0.012 & 0.001 & -0.219 & 0.006 & 0.003 \\
\hline Strengthening exercises & 0.108 & $<0.001$ & 0.004 & & & \\
\hline Upright activities & -0.305 & 0.003 & 0.002 & & & \\
\hline Wheelchair mobility - manual & 0.279 & $<0.001$ & 0.009 & & & \\
\hline Wheelchair mobility - power & -0.287 & 0.002 & 0.002 & -0.837 & 0.001 & 0.005 \\
\hline
\end{tabular}

*Motor and Cognitive FIM were Rasch-transformed.

${ }^{*}$ All patient and treatment variables listed in Tables 1 and 2 were allowed to enter the models. Only statistically significant predictors are reported here; a missing variable name means that the variable did not predict any of the outcomes in this table; a blank cell means that the variable was not a significant predictor for the outcome examined. 


\section{Results}

\section{Patient characteristics}

Table 1 provides patient demographic and injury characteristics for the analytic sample of 1032 patients and for each of the three analysis subgroups. In addition, parallel means and percentages for the four injury groupings used as predictor variables in regression models are presented in the first article in this SCIRehab series. ${ }^{27}$ Table 1

\section{Total time in PT}

Physical therapists documented 58607 hours of treatment (mean 57 hours per patient, $\mathrm{SD}=36$ ) provided during 62953 therapy sessions for the 1032 patients in the analytic subset (used for results reported here).

Associations of PT activities with outcomes at the time of rehabilitation discharge and 1 year postinjury

\section{Discharge FIM motor score}

Patient (demographic and injury) characteristics predict $65 \%$ of the variation in discharge motor FIM score (Table 3). Patients with AIS A, B, or C injuries have lower motor FIM scores than patients with AIS D. Higher admission motor FIM and having an injury that is work related also are strong predictors of higher discharge motor FIM. Older age, longer time from injury to rehabilitation admission and being obese $(\mathrm{BMI} \geq 30)$ are associated with lower discharge motor FIM scores. The $R^{2}$ for this model increases from 0.65 to 0.77 with the addition of PT treatment variables. Higher patient participation scores and more time spent on PT activities of pre-gait and gait training, aquatic and strengthening exercises, patient assessments, and manual wheelchair mobility training are associated with higher scores. More time in PT activities of airway/ respiratory management, educational classes, equipment evaluation/provision, musculoskeletal treatments and modalities, ROM/stretching, upright work (such as using a tilt table or standing frame), and power wheelchair mobility skills is associated with lower scores. Adding rehabilitation center to the model increases the $R^{2}$ only slightly (to 0.78 ).

\section{FIM motor score at 1 year post-injury}

Together, patient characteristics, PT treatment variables and rehabilitation center explain $62 \%$ of the variation in the motor FIM scores at 1 year post-injury. Patient/ injury characteristics explain most of this variation (51\%): injury group (patients with AIS D have higher scores), pre-injury education levels of high school graduation or college and higher admission motor FIM score predict higher FIM scores at 1 year post-injury. Older age, higher admission cognitive FIM scores, longer time from injury to rehabilitation admission, and Medicaid and workers compensation as payers (private payer is the reference group) are associated with lower FIM scores at 1 year post-injury. The addition of PT treatment variables increases the $R^{2}$ from 0.51 to 0.61 . Rehabilitation center adds only 0.01 to the total $R^{2}$. Significant treatment predictors are similar to those predicting higher discharge motor FIM scores (Table 3).

\section{Discharge location}

Most patients (89\%) were discharged to home (Table 4). Predictors of discharge to home ( $c$ statistic for patient and treatment variables $=0.85, \operatorname{Max} R^{2}=0.33$ ) include: higher admission motor FIM, being married, more experience of physical therapists providing treatment, higher patient participation scores, and more time spent in PT equipment evaluation/provision and general education. Older age, race of black and Hispanic, more medical severity (CSI) during rehabilitation and more PT time dedicated to ROM/stretching are associated with discharge to a location other than home. The addition of rehabilitation center as an independent variable increased the $c$ statistic by less than 0.01 and increased the Max $R^{2}$ by 0.02 .

\section{Residential location at 1 year post-injury}

Patient characteristics predict little of the variation in residential location by the time of the injury anniversary (c statistic $=0.55 / \operatorname{Max} R^{2}=0.02$ ). Adding PT treatment variables increases the $c$ statistic to 0.71 (Max $R^{2}=0.12$ ); more time spent in power wheelchair mobility training, therapeutic exercises involving ROM/ stretching and strengthening and attending educational classes that are led by physical therapists are associated with not residing at home at the injury anniversary. The addition of rehabilitation center as a predictor variable increases the c statistic to $0.76\left(\operatorname{Max} R^{2}=0.15\right)$. See Table 4.

\section{Work/school after Injury}

Patients who were students prior to injury are almost five times more likely to work or attend school one year after injury than those who were working and patients who participated more in their therapy are almost twice as likely. Patients who were college-educated were more likely to be working or going to school (Table 4). Other predictors include level of injury (patients with tetraplegia are less likely than patients with AIS D injuries to be in school or working) and injury etiology (patients who were injured in sports-related accidents are over 2.5 times 
Table 4 Prediction of discharge location, place of residence at 1 year post-injury, and likeliness of working or being in school at 1 year post-injury

\begin{tabular}{|c|c|c|c|c|c|c|c|c|c|}
\hline \multirow{4}{*}{$\begin{array}{l}\text { Outcome } \\
\text { No of observations used } \\
\text { Step 1: Pt characteristics: } c \text { statistic/Max } R^{2} \\
\text { Step 2: Pt characteristics + treatments: } \\
\quad \text { c statistic/Max } R^{2}\end{array}$} & \multicolumn{3}{|c|}{ Discharged to home } & \multicolumn{3}{|c|}{ Reside at home at 1 year post-injury } & \multicolumn{3}{|c|}{ Work/school at 1 year post-injury } \\
\hline & \multicolumn{3}{|c|}{ 1031: Yes $=917, \mathrm{No}=114$} & \multicolumn{3}{|c|}{ 878: Yes $=828, \mathrm{No}=50$} & \multicolumn{3}{|c|}{ 856: $Y e s=236, \mathrm{No}=620$} \\
\hline & \multicolumn{3}{|c|}{$0.78 / 0.21$} & \multicolumn{3}{|c|}{$0.55 / 0.20$} & \multicolumn{3}{|c|}{$\begin{aligned} 030 . & \text { res }=230,1 \mathrm{NO}=020 \\
& 0.81 / 0.33\end{aligned}$} \\
\hline & \multicolumn{3}{|c|}{$0.85 / 0.33$} & \multicolumn{3}{|c|}{$0.71 / 0.12$} & \multicolumn{3}{|c|}{$0.83 / 0.36$} \\
\hline $\begin{array}{l}\text { Step 3: Pt characteristics + treatments }+ \\
\quad \text { center identity: c statistic/Max } R^{2}\end{array}$ & \multicolumn{3}{|c|}{$0.85 / 0.35$} & \multicolumn{3}{|c|}{$0.76 / 0.15$} & \multicolumn{3}{|c|}{$0.83 / 0.36$} \\
\hline Independent variables* & $\begin{array}{l}\text { Parameter } \\
\text { estimate }\end{array}$ & $\begin{array}{l}\text { Odds } \\
\text { ratio } \\
\text { estimate }\end{array}$ & $P$ value & $\begin{array}{l}\text { Parameter } \\
\text { estimate }\end{array}$ & $\begin{array}{l}\text { Odds } \\
\text { ratio } \\
\text { estimate }\end{array}$ & $P$ value & $\begin{array}{l}\text { Parameter } \\
\text { estimate }\end{array}$ & $\begin{array}{l}\text { Odds } \\
\text { ratio } \\
\text { estimate }\end{array}$ & $P$ value \\
\hline Neurological group & & & & & & & - & - & 0.002 \\
\hline C1-4 ABC & & & & & & & -1.512 & 0.221 & $<0.001$ \\
\hline C5-8 ABC & & & & & & & -0.726 & 0.484 & 0.036 \\
\hline Para ABC & & & & & & & -0.328 & 0.720 & 0.232 \\
\hline All Ds (reference) & & & & & & & 0.000 & - & - \\
\hline $\begin{array}{l}\text { Admission FIM motor score - Rasch } \\
\text { transformed }\end{array}$ & 0.046 & 1.047 & $<0.001$ & & & & 0.023 & 1.023 & 0.049 \\
\hline Comprehensive severity index (CSI) score & -0.013 & 0.987 & 0.003 & & & & & & \\
\hline Traumatic etiology & & & & & & & - & - & 0.035 \\
\hline Medical/surgical/other & & & & & & & -0.399 & 0.671 & 0.447 \\
\hline Violence & & & & & & & 0.105 & 1.111 & 0.753 \\
\hline Sports & & & & & & & 0.922 & 2.515 & 0.002 \\
\hline Fall & & & & & & & 0.063 & 1.065 & 0.802 \\
\hline Vehicular (reference) & & & & & & & 0.000 & - & - \\
\hline Age at injury & -0.039 & 0.962 & $<0.001$ & & & & -0.022 & 0.978 & 0.014 \\
\hline Marital status $=$ married & 0.679 & 1.971 & 0.011 & & & & & & \\
\hline Race & - & - & 0.010 & & & & & & \\
\hline All other minorities & -0.873 & 0.418 & 0.059 & & & & & & \\
\hline Black & -0.603 & 0.547 & 0.024 & & & & & & \\
\hline Hispanic & -1.317 & 0.268 & 0.013 & & & & & & \\
\hline White (reference) & 0.000 & - & - & & & & & & \\
\hline Employment status at injury & & & & & & & - & - & $<0.001$ \\
\hline Unemployed/other & & & & & & & -0.690 & 0.502 & 0.070 \\
\hline Student & & & & & & & 1.512 & 4.536 & $<0.001$ \\
\hline Retired & & & & & & & -0.709 & 0.492 & 0.218 \\
\hline Working (reference) & & & & & & & 0.000 & - & - \\
\hline Highest education achieved & & & & & & & - & - & $<0.001$ \\
\hline Other/unknown & & & & & & & ** & ** & $\star \star *$ \\
\hline High school & & & & & & & 0.218 & 1.243 & 0.435 \\
\hline College & & & & & & & 1.071 & 2.917 & $<0.001$ \\
\hline$<12$ Years (reference) & & & & & & & 0.000 & - & - \\
\hline Primary language is English & & & & 1.149 & 3.156 & 0.013 & & & \\
\hline Primary payer & & & & & & & - & - & $<0.001$ \\
\hline Medicare & & & & & & & -0.880 & 0.415 & 0.158 \\
\hline Medicaid & & & & & & & -0.866 & 0.421 & 0.002 \\
\hline Worker's compensation & & & & & & & -1.031 & 0.357 & 0.005 \\
\hline
\end{tabular}




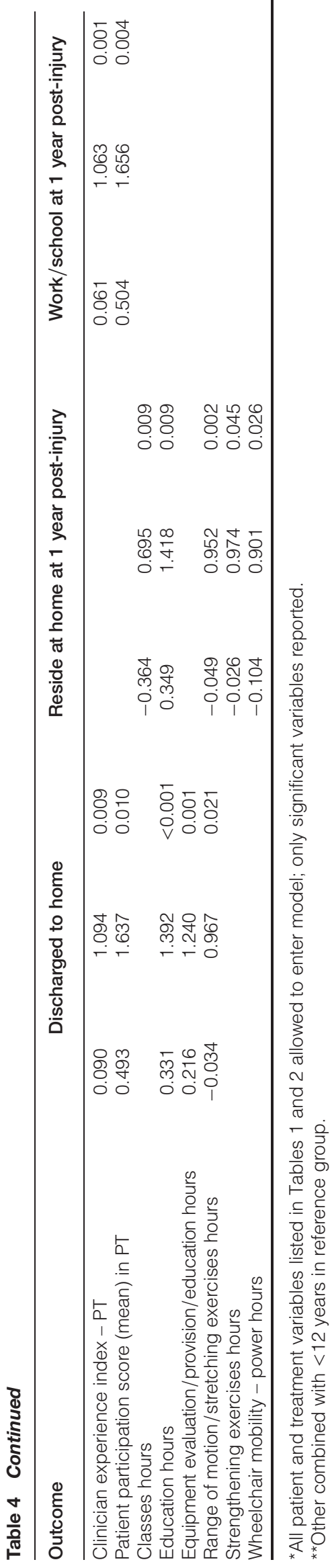

more likely to work/attend school than those with a vehicular etiology). Patient variables explain most of this variation (the $c$ statistic increases only from 0.81 to 0.83 , Max $R^{2}$ increases from 0.33 to 0.36 with the addition of treatment variables); the addition of rehabilitation center does not strengthen the model.

\section{Societal participation}

The combination of patient characteristics and PT treatments is predictive of the Physical Independence $\left(R^{2}=\right.$ $0.48)$, Mobility $\left(R^{2}=0.32\right)$ and Occupation $\left(R^{2}=\right.$ 0.27 ) dimensions of the CHART; less predictive power is seen for the dimension Social Integration $\left(R^{2}=\right.$ $0.16)$. See Table 5. Younger age, having a college education, higher admission motor FIM, and being married are associated with higher scores in all or most dimensions. Payer is also a significant predictor: having Medicaid is associated with lower Social Integration, Occupation, and Mobility scores, and having workers compensation is associated with lower Physical Integration scores. Student status pre-injury is associated with higher Occupation and Mobility scores; being retired is associated with higher Social Integration and lower Occupation scores. Higher patient participation score in PT sessions is associated with higher scores in all dimensions; more time spent in classes led by physical therapists is associated with lower scores (all dimensions except Mobility). Additional PT treatment variables associated with higher CHART Mobility scores include more time spent in gait training, strengthening exercises and equipment evaluations/provision. More time in gait training is also associated with higher Occupation scores. The addition of rehabilitation center as a predictor variable adds 0.01 or less to the $R^{2}$ for each model.

\section{Mood state and life satisfaction}

Patient characteristics, PT treatments and rehabilitation center are weak predictors of depressive symptomology, as measured by the PHQ-9 $\left(R^{2}=0.08\right)$, and life satisfaction, as measured by the SWLS $\left(R^{2}=0.11\right)$ at 1 year post-injury. A higher PHQ-9 score indicates greater depressive symptomology and a higher SWLS score indicates greater satisfaction with life. Most of this variation is explained by patient characteristics. (Regression model results not shown.) Patients who are older or unemployed prior to injury have higher PHQ-9 scores and lower SWLS scores. Patients who are obese or who have high school or college educations have lower PHQ-9 scores; longer time from trauma to rehabilitation admission, work-related injuries and more time spent on power wheelchair mobility are associated with higher 
Table 5 Prediction of social participation at 1 year post-injury

\begin{tabular}{|c|c|c|c|c|c|c|c|c|c|c|c|c|}
\hline \multirow{2}{*}{$\begin{array}{l}\text { Outcome } \\
\text { Observations used }\end{array}$} & \multicolumn{3}{|c|}{ CHART: Physical Independence } & \multicolumn{3}{|c|}{ CHART: Social Integration } & \multicolumn{3}{|c|}{ CHART: Occupation } & \multicolumn{3}{|c|}{ CHART: Mobility } \\
\hline & & 856 & & & 830 & & & 845 & & & 843 & \\
\hline Step 1: Pt characteristics: adj. $R^{2}$ & & 0.41 & & & 0.12 & & & 0.22 & & & 0.26 & \\
\hline $\begin{array}{l}\text { Step 2: Pt characteristics + } \\
\quad \text { treatments: adj. } R^{2}\end{array}$ & & 0.48 & & & 0.16 & & & 0.27 & & & 0.32 & \\
\hline $\begin{array}{l}\text { Step 3: Pt characteristics + } \\
\text { treatments + center identity: } \\
\text { adj. } R^{2}\end{array}$ & & 0.48 & & & 0.17 & & & 0.28 & & & 0.32 & \\
\hline Independent variables* & $\begin{array}{l}\text { Parameter } \\
\text { estimate }\end{array}$ & $\begin{array}{l}P \\
\text { value }\end{array}$ & $\begin{array}{l}\text { Semi } \\
\text { partial } \\
\text { omega }^{2}\end{array}$ & $\begin{array}{l}\text { Parameter } \\
\text { estimate }\end{array}$ & $\begin{array}{l}P \\
\text { value }\end{array}$ & $\begin{array}{l}\text { Semi } \\
\text { partial } \\
\text { omega }^{2}\end{array}$ & $\begin{array}{l}\text { Parameter } \\
\text { estimate }\end{array}$ & $\begin{array}{c}P \\
\text { value }\end{array}$ & $\begin{array}{l}\text { Semi } \\
\text { partial } \\
\text { omega }^{2}\end{array}$ & $\begin{array}{l}\text { Parameter } \\
\text { estimate }\end{array}$ & $\begin{array}{l}P \\
\text { value }\end{array}$ & $\begin{array}{l}\text { Semi } \\
\text { partial } \\
\text { omega }^{2}\end{array}$ \\
\hline Neurological group & - & $<0.001$ & 0.016 & & & & & & & & & \\
\hline C1-4 ABC & -17.636 & $<0.001$ & - & & & & & & & & & \\
\hline C5-8 ABC & -4.665 & 0.225 & - & & & & & & & & & \\
\hline Para ABC & 1.074 & 0.733 & - & & & & & & & & & \\
\hline All Ds (reference) & 0.000 & - & - & & & & & & & & & \\
\hline $\begin{array}{l}\text { Admission FIM motor - Rasch } \\
\text { transformed }\end{array}$ & 0.767 & $<0.001$ & 0.021 & 0.157 & 0.009 & 0.006 & 0.758 & $<0.001$ & 0.044 & 0.422 & $<0.001$ & 0.032 \\
\hline $\begin{array}{l}\text { Admission FIM cognitive - Rasch } \\
\text { transformed }\end{array}$ & & & & 0.099 & 0.013 & 0.005 & & & & & & \\
\hline $\begin{array}{l}\text { Days from trauma to rehabilitation } \\
\text { admission }\end{array}$ & -0.219 & $<0.001$ & 0.024 & & & & & & & -0.095 & $<0.001$ & 0.011 \\
\hline Traumatic etiology & - & 0.001 & 0.009 & & & & & & & & & \\
\hline Medical/surgical/other & -12.731 & 0.014 & - & & & & & & & & & \\
\hline Violence & -2.528 & 0.490 & - & & & & & & & & & \\
\hline Sports & -12.341 & $<0.001$ & - & & & & & & & & & \\
\hline Fall & -1.911 & 0.454 & - & & & & & & & & & \\
\hline Vehicular (reference) & 0.000 & - & - & & & & & & & & & \\
\hline $\begin{array}{l}\text { Age at injury } \\
\text { Gender is male }\end{array}$ & -0.286 & $<0.001$ & 0.008 & -0.294 & $<0.001$ & 0.023 & $\begin{array}{l}-0.432 \\
-10.482\end{array}$ & $\begin{array}{l}<0.001 \\
<0.001\end{array}$ & $\begin{array}{l}0.014 \\
0.010\end{array}$ & -0.450 & $<0.001$ & 0.038 \\
\hline Marital status is married & & & & 8.151 & $<0.001$ & 0.025 & 6.930 & 0.011 & 0.005 & 4.187 & 0.015 & 0.004 \\
\hline Race & - & 0.025 & 0.004 & & & & & & & - & 0.026 & 0.005 \\
\hline All other minorities & -9.798 & 0.032 & - & & & & & & & -4.274 & 0.215 & - \\
\hline Black & -5.529 & 0.037 & - & & & & & & & -5.346 & 0.004 & - \\
\hline Hispanic & 5.112 & 0.388 & - & & & & & & & -2.094 & 0.662 & - \\
\hline White (reference) & 0.000 & - & - & & & & & & & 0.000 & - & - \\
\hline Occupation status at injury & & & & - & $<0.001$ & 0.018 & - & 0.008 & 0.008 & - & 0.016 & 0.006 \\
\hline Unemployed/other & & & & -5.609 & 0.016 & - & -0.128 & 0.974 & - & -3.020 & 0.225 & - \\
\hline Student & & & & 0.944 & 0.684 & - & 9.852 & 0.013 & - & 6.477 & 0.009 & - \\
\hline Retired & & & & 10.581 & 0.001 & - & -14.066 & 0.012 & - & 0.507 & 0.884 & - \\
\hline Working (reference) & & & & 0.000 & - & - & 0.000 & - & - & 0.000 & - & - \\
\hline Highest education achieved & - & $<0.001$ & 0.008 & - & 0.015 & 0.006 & - & $<0.001$ & 0.015 & - & $<0.001$ & 0.018 \\
\hline High School & 7.837 & 0.003 & - & 0.945 & 0.614 & - & 3.904 & 0.221 & - & 3.041 & 0.133 & - \\
\hline College & 12.365 & $<0.001$ & - & 5.267 & 0.017 & - & 14.401 & $<0.001$ & - & 10.530 & $<0.001$ & - \\
\hline $\begin{array}{l}<12 \text { Years/other/unknown } \\
\text { (reference) }\end{array}$ & 0.000 & - & - & 0.000 & - & - & 0.000 & - & - & 0.000 & - & - \\
\hline Primary language is English & & & & & & & 13.858 & 0.008 & 0.005 & 12.213 & 0.001 & 0.009 \\
\hline
\end{tabular}


Table 5 Continued

\begin{tabular}{|c|c|c|c|c|c|c|c|c|c|c|c|c|}
\hline \multirow{2}{*}{$\begin{array}{l}\text { Outcome } \\
\text { Primary payer }\end{array}$} & \multicolumn{3}{|c|}{ CHART: Physical Independence } & \multicolumn{3}{|c|}{ CHART: Social Integration } & \multicolumn{3}{|c|}{ CHART: Occupation } & \multicolumn{3}{|c|}{ CHART: Mobility } \\
\hline & - & 0.016 & 0.005 & - & 0.008 & 0.009 & - & 0.037 & 0.005 & - & 0.009 & 0.007 \\
\hline Medicare & -5.020 & 0.256 & - & -3.930 & 0.232 & - & 3.663 & 0.518 & - & 3.625 & 0.309 & - \\
\hline Medicaid & 0.362 & 0.892 & - & -6.257 & 0.001 & - & -7.457 & 0.019 & - & -6.345 & 0.002 & - \\
\hline Worker's compensation & -10.337 & 0.002 & - & -1.417 & 0.532 & - & -7.134 & 0.071 & - & -0.172 & 0.945 & - \\
\hline $\begin{array}{l}\text { Private insurance/pay } \\
\quad \text { (reference) }\end{array}$ & 0.000 & - & - & 0.000 & - & - & 0.000 & - & - & 0.000 & - & - \\
\hline $\begin{array}{l}\text { Patient participation score - PT } \\
\text { PT hours of specific treatments: }\end{array}$ & 4.420 & 0.012 & 0.003 & 3.482 & 0.003 & 0.008 & 9.715 & $<0.001$ & 0.019 & 4.707 & $<0.001$ & 0.010 \\
\hline $\begin{array}{l}\text { Airway/respiratory management } \\
\text { Assessment }\end{array}$ & $\begin{array}{c}-1.986 \\
1.880\end{array}$ & $\begin{array}{l}0.031 \\
0.001\end{array}$ & $\begin{array}{l}0.002 \\
0.006\end{array}$ & & & & & & & -1.754 & 0.009 & 0.005 \\
\hline $\begin{array}{l}\text { Classes provided by PT } \\
\text { Education }\end{array}$ & -2.595 & 0.037 & 0.002 & $\begin{array}{c}-1.897 \\
0.951\end{array}$ & $\begin{array}{l}0.027 \\
0.013\end{array}$ & $\begin{array}{l}0.004 \\
0.005\end{array}$ & -4.860 & 0.001 & 0.009 & & & \\
\hline $\begin{array}{l}\text { Equipment evaluation/ provision/ } \\
\text { education }\end{array}$ & & & & & & & & & & 0.647 & 0.015 & 0.004 \\
\hline Gait & & & & & & & 0.590 & 0.005 & 0.006 & 0.495 & 0.001 & 0.009 \\
\hline Pre-gait & 2.754 & $<0.001$ & 0.010 & & & & & & & & & \\
\hline $\begin{array}{l}\text { Skin management } \\
\text { Endurance exercises }\end{array}$ & -2.449 & 0.014 & 0.003 & $\begin{array}{c}-1.612 \\
0.471\end{array}$ & $\begin{array}{l}0.016 \\
<0.001\end{array}$ & $\begin{array}{l}0.005 \\
0.013\end{array}$ & & & & & & \\
\hline $\mathrm{ROM} /$ stretching & -0.514 & 0.001 & 0.006 & & & & & & & -0.355 & 0.002 & 0.007 \\
\hline Strengthening & 0.236 & 0.032 & 0.002 & & & & & & & 0.207 & 0.010 & 0.005 \\
\hline Wheelchair mobility-power & -1.289 & 0.007 & 0.004 & & & & -1.315 & 0.013 & 0.005 & & & \\
\hline
\end{tabular}

*All patient and treatment variables listed in Tables 1 and 2 were allowed to enter the models. Only statistically significant predictors are reported here; a missing variable name means that variable did not predict any of the outcomes in this table; a blank cell means that the variable was not a significant predictor for the outcome examined. 
PHQ-9 scores. Patients with high tetraplegia or paraplegia and those with Medicaid or workers compensation as their primary payer have lower SWLS scores; patients who were more engaged in PT sessions and were treated by physical therapists with more experience in SCI rehabilitation report higher SWLS scores. More time spent in power wheelchair mobility training during PT is associated with lower SWLS scores.

\section{Rehospitalization}

Thirty-six percent of patients were rehospitalized between rehabilitation discharge and 1 year post-injury (Table 6). More time spent on PT activities of gait, $\mathrm{ROM} /$ stretching, strengthening exercises and general education, along with higher motor FIM scores at the time of rehabilitation admission and being a student pre-injury are associated with less rehospitalization. Higher medical severity during rehabilitation, having Medicaid as the primary payer and more time spent in power wheelchair mobility training are associated with likelihood of rehospitalization $(c$ statistic $=0.73$, Max $R^{2}=0.19$ ). The addition of rehabilitation center as a predictor variable improves the explanatory power by only 0.01 .

\section{Pressure sores at 1 year post-injury}

More time spent in PT on gait, upright activities, and strengthening exercises, along with higher motor FIM scores and more participation during PT sessions are associated with less reporting of pressure ulcers at 1 year post-injury $\left(c\right.$ statistic $=0.73$, $\operatorname{Max} R^{2}=0.15$; see Table 6). The addition of rehabilitation center as a predictor variable increases the c statistic by 0.01 (Max $R^{2}$ by 0.02 ).

\section{Model validation}

Linear regression models that validated well (relative shrinkage $<0.1)$ include: motor FIM at discharge and 1 year post-injury, CHART Physical Independence and Life Satisfaction. Models for CHART Occupation and Mobility validated moderately well (relative shrinkage $0.1-0.2$ ). Two models validated poorly (relative shrinkage >0.2): CHART Social Integration and PHQ-9. For dichotomous outcomes, all but one of the models validated well (HL $P$ value $>0.1$ for both): the only exception was discharge destination at discharge, which showed lack of fit (HL $P$ value $<0.05$ for one or both models).

\section{Subgroup analyses}

The FIM outcomes used for full analytic sample analyses were used for subgroup analyses and, in addition, specific components of the FIM were examined.

\section{Patients with motor complete low tetraplegia} $\left(C_{5}-8\right)$

There are 78 patients in the analytic (75\%) SCIRehab dataset with $\mathrm{C} 5-\mathrm{C} 8$ motor complete injuries at both admission and discharge. These patients have similar characteristics as patients in the full dataset: predominately male, white and English speaking with a BMI $<30$ and a mean age of 31.7 years (Table 1). Most patients were working at the time of injury, had obtained at least a high school diploma or GED and were not married. The most common causes of injury were motor vehicle accidents and sports; most injuries were not work-related. Private insurance was the most common payer type. Patients in this group spent the most time in PT sessions working on strengthening, $\mathrm{ROM} /$ stretching and transfer training (Table 2).

\section{Transfer component of discharge motor FIM}

Table 7 shows that patient characteristics alone predict $37 \%$ of the variation in the transfer item; C5 and C6 injury levels are associated with a lower score (compared to $\mathrm{C} 7-8$ ), as is longer time from injury to rehabilitation. Higher admission FIM transfer score is the only positive patient predictor. The addition of PT treatments increases the predictive power to $61 \%$. The strongest predictor is time spent on manual wheelchair mobility $(P<0.001)$. More PT time spent on patient assessment is associated with lower transfer item scores. The addition of rehabilitation center to the models did not increase the $R^{2}$.

Transfer component of motor FIM at 1 year post-injury The addition of PT treatment variables to patient characteristics increases the $R^{2}$ for predicting the transfer item on the 1 year post-injury motor FIM from 0.28 to 0.37 . Higher admission motor FIM scores (but not the independent variable for the transfer component of the motor FIM at admission) and more time spent in PT working on transfers is associated with a higher score. Longer time from injury to rehabilitation admission and more time working on upright activities are associated with lower scores. The addition of rehabilitation center did not strengthen the model.

\section{Patients with motor complete paraplegia ( $\left.T_{1}-9\right)$}

There are 158 patients in the analytic (75\%) SCIRehab dataset with T1-T9 motor complete injuries at both admission and discharge and no brachial plexus injuries or upper extremity fractures. These patients are predominately male, white and English speaking with a $\mathrm{BMI}<30$ and a mean age of 31.5 (Table 1). The most common cause of SCI was motor vehicle accident. A majority of patients had obtained a high school diploma or GED and was employed at the time of 
Table 6 Prediction of rehospitalization between DC and 1 year post-injury and pressure sore(s) at 1 year post-injury

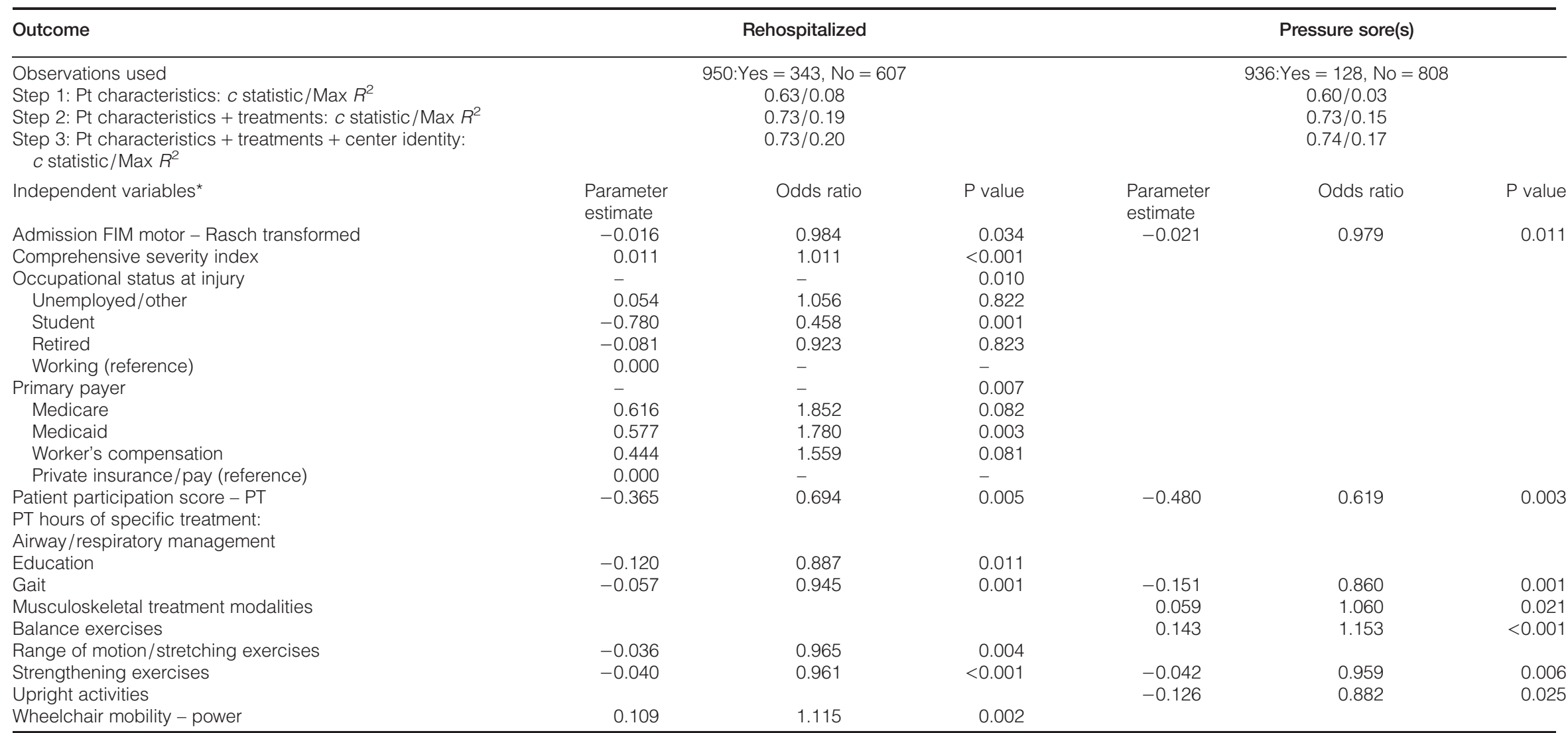

*All patient and treatment variables listed in Tables 1 and 2 were allowed to enter the models. Only statistically significant predictors are reported here; a missing variable name means that the variable did not predict any of the outcomes in this table; a blank cell means that the variable was not a significant predictor for the outcome examined. 
Table 7 Prediction of transfer component of motor FIM* at discharge from rehabilitation and at 1 year post-injury for patients with motor complete low tetraplegia (C5-8)

\begin{tabular}{|c|c|c|c|c|c|c|}
\hline \multirow{6}{*}{$\begin{array}{l}\text { Outcome } \\
\text { Observations used } \\
\text { Step 1: Pt characteristics: adj. } R^{2} \\
\text { Step 2: Pt characteristics + treatments: adj. } R^{2} \\
\text { Step 3: Pt characteristics + treatments + center identity: adj. } R^{2} \\
\text { Independent variables** }\end{array}$} & \multicolumn{3}{|c|}{ FIM transfer score* at discharge } & \multicolumn{3}{|c|}{ FIM transfer score ${ }^{\star}$ at one year } \\
\hline & & 78 & & & 67 & \\
\hline & & 0.37 & & & 0.28 & \\
\hline & & 0.61 & & & 0.37 & \\
\hline & & 0.61 & & & 0.36 & \\
\hline & $\begin{array}{l}\text { Parameter } \\
\text { estimate }\end{array}$ & $P$ value & $\begin{array}{l}\text { Semi partial } \\
\text { omega }^{2}\end{array}$ & $\begin{array}{c}\text { Parameter } \\
\text { estimate }\end{array}$ & $P$ value & $\begin{array}{l}\text { Semi partial } \\
\text { omega }^{2}\end{array}$ \\
\hline Neurological group & - & $<0.001$ & 0.114 & & & \\
\hline C5 & -13.400 & $<0.001$ & - & & & \\
\hline C6 & -8.254 & 0.014 & - & & & \\
\hline C7-8 (reference) & 0.000 & - & - & & & \\
\hline Admission FIM motor ${ }^{*}$ & & & & 1.765 & $<0.001$ & 0.228 \\
\hline Admission FIM transfer score* & 0.776 & 0.006 & 0.035 & & & \\
\hline $\begin{array}{l}\text { Days from trauma to rehabilitation admission } \\
\text { PT hours of specific treatments: }\end{array}$ & -0.098 & 0.038 & 0.018 & -0.300 & 0.040 & 0.032 \\
\hline Assessment & -2.551 & 0.002 & 0.045 & & & \\
\hline Transfers & & & & 2.093 & 0.003 & 0.078 \\
\hline Upright activities & & & & -3.244 & 0.033 & 0.036 \\
\hline Wheelchair mobility - manual & 1.794 & $<0.001$ & 0.233 & & & \\
\hline
\end{tabular}

${ }^{*}$ FIM motor and transfer scores were Rasch-transformed.

${ }^{* *}$ All patient and treatment variables listed in Tables 1 and 2 were allowed to enter the models except the injury being work related and time in PT activity of gait training due to insufficient representation in the group; additional variables allowed to enter model include Rasch-transformed admission transfer FIM score and the number of PT sessions focused on each type of transfer (to/from wheelchair, chair, mat, bed, vehicle, and floor); only statistically significant predictors are reported here; a missing variable name means that the variable did not predict any of the outcomes in this table; a blank cell means that the variable was not a significant predictor for the outcome examined. 
their injury, but most injuries were not work-related. Most patients were not married at the time of injury. Private insurance was the most common payer group $(63 \%)$. Patients in this subgroup spent the most time in PT sessions working on transfer training, strengthening and manual wheelchair mobility (Table 2).

\section{Discharge motor FIM}

Regression modeling demonstrates over a two-fold increase in prediction of discharge motor FIM scores when PT treatment variables are added to patient characteristics (Table 8). Demographic/injury variables explain $30 \%$ of the variation in the discharge motor FIM. Higher admission motor FIM score and being male are associated with higher scores; being married and obese at the time of injury are associated with lower scores. The addition of PT treatment variables increases the $R^{2}$ from 0.30 to 0.64 . Higher patient participation scores during PT sessions and more time spent on endurance exercises and manual wheelchair mobility training are associated with higher scores; more time spent by physical therapists on patient assessment, more time in bed mobility activities, and more time patients spend in classes led by physical therapists are associated with lower scores. The addition of rehabilitation center increases the $R^{2}$ to 0.71 .

\section{Motor FIM at 1 year post-injury}

Patient variables (etiology of falls, younger age, being male, and having English as a primary language are associated with higher scores) account for $27 \%$ of the explained variation (Table 8 ). The $R^{2}$ increases to 0.45 with the addition of PT treatments. Better participation in PT sessions during rehabilitation and more time spent working on strengthening are associated with higher scores; more time that physical therapists spend participating in interdisciplinary conferences and performing assessments, along with more time that patients spend in educational classes led by a physical therapist and in balance activities are associated with lower scores. The addition of rehabilitation center increases the $R^{2}$ to 0.46 .

\section{Patients with AIS D injuries}

There are 158 patients in the analytic (75\%) SCIRehab dataset with injuries classified as AIS D at both rehabilitation admission and discharge. The majority of patients in this subgroup (128) had tetraplegia and 30 had paraplegia.

Table 8 Prediction of Motor FIM* at discharge from rehabilitation and at 1 year post-injury for patients with motor complete paraplegia (T1-9)

\begin{tabular}{|c|c|c|c|c|c|c|}
\hline \multirow{2}{*}{$\begin{array}{l}\text { Outcome } \\
\text { Observations used }\end{array}$} & \multicolumn{3}{|c|}{ Motor FIM at discharge* } & \multicolumn{3}{|c|}{ Motor FIM at one year* } \\
\hline & & 158 & & & 132 & \\
\hline Step 1: Pt characteristics: adj. $R^{2}$ & & 0.30 & & & 0.27 & \\
\hline Step 2: Pt characteristics + treatments: adj. $R^{2}$ & & 0.64 & & & 0.45 & \\
\hline Step 3: Pt characteristics + treatments + center identity: adj. $R^{2}$ & & 0.71 & & & 0.46 & \\
\hline Independent variables** & $\begin{array}{l}\text { Parameter } \\
\text { estimate }\end{array}$ & $P$ value & $\begin{array}{l}\text { Semi partial } \\
\text { omega }^{2}\end{array}$ & $\begin{array}{l}\text { Parameter } \\
\text { estimate }\end{array}$ & $P$ value & $\begin{array}{l}\text { Semi partia } \\
\text { omega }^{2}\end{array}$ \\
\hline Admission FIM motor & 0.185 & 0.004 & 0.018 & & & \\
\hline Traumatic etiology & & & & - & 0.001 & 0.055 \\
\hline All other & & & & -2.799 & 0.091 & - \\
\hline Fall & & & & 5.249 & 0.003 & - \\
\hline Vehicular (reference) & & & & 0.000 & - & - \\
\hline Age at injury & & & & -0.310 & $<0.001$ & 0.180 \\
\hline Gender is male & 3.565 & $<0.001$ & 0.048 & 4.071 & 0.007 & 0.028 \\
\hline Marital status is married & -1.396 & 0.031 & 0.009 & & & \\
\hline $\mathrm{BMI} \geq 30$ & -2.035 & 0.007 & 0.015 & & & \\
\hline Primary language is English & & & & 6.438 & 0.016 & 0.021 \\
\hline $\begin{array}{l}\text { Patient participation score - PT } \\
\text { PT hours in specific treatments: }\end{array}$ & 1.918 & $<0.001$ & 0.034 & 2.604 & 0.009 & 0.025 \\
\hline Assessment & -0.536 & 0.044 & 0.007 & -1.097 & 0.029 & 0.016 \\
\hline Bed mobility & -0.521 & $<0.001$ & 0.027 & & & \\
\hline Classes provided by PT & -1.623 & $<0.001$ & 0.028 & -2.083 & 0.021 & 0.019 \\
\hline Interdisciplinary conferencing on patient's behalf & & & & -1.170 & 0.002 & 0.039 \\
\hline Balance exercises & & & & -0.671 & 0.030 & 0.016 \\
\hline Endurance exercises & 0.411 & 0.001 & 0.026 & & & \\
\hline Strengthening exercises & & & & 0.244 & 0.011 & 0.024 \\
\hline Wheelchair mobility - manual & 0.224 & 0.001 & 0.026 & & & \\
\hline
\end{tabular}

${ }^{*}$ Motor FIM was Rasch-transformed

${ }^{* *}$ All patient and treatment variables listed in Tables 1 and 2 were allowed to enter model except ventilator use on admission to rehabilitation and time in PT activity of airway/respiratory management due to insufficient representation in the group; Only statistically significant predictors are reported here; a missing variable name means that the variable did not predict any of the outcomes in this table; a blank cell means that the variable was not a significant predictor for the outcome examined. 
Teeter et al. Relationship of physical therapy to outcomes

Table 9 Prediction of motor FIM* at discharge from rehabilitation and at 1 year post-injury for patients with AIS D injuries

\begin{tabular}{|c|c|c|c|c|c|c|}
\hline Outcome & \multicolumn{3}{|c|}{ Motor $\mathrm{FIM}^{\star}$ at discharge } & \multicolumn{3}{|c|}{ Motor $\mathrm{FIM}^{\star}$ at 1 year } \\
\hline Observations used & \multicolumn{3}{|c|}{158} & \multicolumn{3}{|c|}{135} \\
\hline Step 1: Pt characteristics: adjusted $R^{2}$ & \multicolumn{3}{|c|}{0.36} & \multicolumn{3}{|c|}{0.20} \\
\hline $\begin{array}{l}\text { Step 2: Pt characteristics + treatments: adjusted } \\
R^{2}\end{array}$ & \multicolumn{3}{|c|}{0.54} & \multicolumn{3}{|c|}{0.35} \\
\hline $\begin{array}{l}\text { Step 3: Pt characteristics + treatments + } \\
\quad \text { center identity: adjusted } R^{2}\end{array}$ & \multicolumn{3}{|c|}{0.59} & \multicolumn{3}{|c|}{0.41} \\
\hline Independent variables ${ }^{\star *}$ & $\begin{array}{l}\text { Parameter } \\
\text { estimate }\end{array}$ & $P$ value & $\begin{array}{l}\text { Semi partial } \\
\text { omega }^{2}\end{array}$ & $\begin{array}{l}\text { Parameter } \\
\text { estimate }\end{array}$ & $P$ value & $\begin{array}{l}\text { Semi partial } \\
\text { omega }^{2}\end{array}$ \\
\hline Admission FIM motor* & 0.275 & $<0.001$ & 0.072 & & & \\
\hline Days from trauma to rehabilitation admission & & & & 0.257 & 0.027 & 0.019 \\
\hline Age at injury & -0.163 & $<0.001$ & 0.077 & -0.323 & $<0.001$ & 0.055 \\
\hline $\begin{array}{l}\text { Patient participation score - PT } \\
\text { PT hours in specific treatments: }\end{array}$ & 2.575 & 0.009 & 0.019 & 9.509 & 0.001 & 0.055 \\
\hline Assessment & 1.516 & $<0.001$ & 0.071 & & & \\
\hline Bed mobility & -2.428 & $<0.001$ & 0.050 & -5.685 & 0.001 & 0.050 \\
\hline Classes provided by PT & & & & -8.579 & 0.015 & 0.024 \\
\hline
\end{tabular}

*Motor FIM was Rasch-transformed.

${ }^{* *}$ All patient and treatment variables listed in Tables 1 and 2 were allowed to enter the models except ventilator use at admission to rehabilitation and time in PT activities of airway/respiratory management and wound care due to insufficient representation in the group; additional variables allowed to enter model include admission lower extremity motor score (LEMS) and change in LEMS from admission to discharge. Only statistically significant predictors are reported here; a missing variable name means that the variable did not predict any of the outcomes in this table; a blank cell means that the variable was not a significant predictor for the outcome examined.

Compared to the full SCIRehab sample, these patients are older, more were injured in a fall (or by a falling object) and more patients are retired (Table 1). They also have higher admission motor and cognitive FIM scores, lower medical severity (as measured by the CSI) and shorter lengths of stay. These patients spent the most time in PT on strengthening activities and gait training (Table 2).

\section{Discharge motor FIM}

Patient characteristics explain $36 \%$ of the variation in FIM motor scores (Table 9). When PT treatments are added to the model, the predictive power increases to 54\%. A higher admission motor FIM score, higher patient participation scale score and more time spent by physical therapists performing patient assessment are associated with higher scores; older age and more time spent in bed mobility activities are associated with lower scores. The addition of rehabilitation center increased the $R^{2}$ to 0.59 .

\section{Motor FIM at 1 year post-injury}

A similar increase in the adjusted $R^{2}$ is seen for the motor FIM score at 1 year post-injury when PT

\section{Table 10 Prediction of FIM mode of locomotion at discharge from rehabilitation for patients with AIS D injuries}

\begin{tabular}{|c|c|c|c|}
\hline Outcome & \multicolumn{3}{|c|}{ Discharge FIM locomotion mode walk/Both } \\
\hline $\begin{array}{l}\text { Observations used } \\
\text { Step 1: Pt characteristics: c statistic/Max } R^{2} \\
\text { Step 2: Pt characteristics + treatments: c statistic/Max } R^{2} \\
\text { Step 3: Pt characteristics + treatments + center identity: c statistic/Max } R^{2}\end{array}$ & & $\begin{array}{l}\text { Yes }=96, \mathrm{No}=47 \\
0.80 / 0.35 \\
0.88 / 0.52 \\
0.90 / 0.58\end{array}$ & \\
\hline $\begin{array}{l}\text { Independent Variables* } \\
\text { Admission Lower Extremity Motor Score } \\
\text { Change from Admission to DC Lower Extremity Motor Score } \\
\text { Rehabilitation length of stay } \\
\text { PT hours of specific treatments: }\end{array}$ & $\begin{array}{c}\text { Parameter estimate } \\
0.192 \\
0.185 \\
-0.095\end{array}$ & $\begin{array}{l}\text { Odds Ratio Estimate } \\
\begin{array}{l}1.211 \\
1.204 \\
0.910\end{array}\end{array}$ & $\begin{array}{r}\text { P Value } \\
<0.001 \\
0.001 \\
<0.001\end{array}$ \\
\hline $\begin{array}{l}\text { Interdisciplinary conferencing on patient's behalf } \\
\text { Balance exercises }\end{array}$ & $\begin{array}{l}0.497 \\
0.427\end{array}$ & $\begin{array}{l}1.644 \\
1.533\end{array}$ & $\begin{array}{l}0.014 \\
0.009\end{array}$ \\
\hline
\end{tabular}

*All patient and treatment variables listed in Tables 1 and 2 were allowed to enter the models except ventilator use at admission to rehabilitation and time in PT activities of airway/respiratory management and wound care due to insufficient representation in the group; additional variables allowed to enter model include admission lower extremity motor score (LEMS) and change in LEMS from admission to discharge. Only statistically significant predictors are reported here; a missing variable name means that the variable did not predict any of the outcomes in this table; a blank cell means that the variable was not a significant predictor for the outcome examined 
treatments are added to patient characteristics (from 0.20 to 0.35 ; see Table 9). More days from trauma to rehabilitation admission and higher mean patient participation scores are positive predictors. Older age and more time spent on bed mobility training and in classes are negative predictors. The addition of rehabilitation center as an independent variable increases the $R^{2}$ to 0.41 .

\section{Locomotion mode at discharge}

The majority $(51 \%)$ of patients had a locomotion mode on the discharge motor FIM of "walk," $16 \%$ had "both" and $33 \%$ of patients were classified as having "wheelchair" as their locomotion mode. While much of the variance is explained by patient characteristics, the addition of treatment variables further increases the ability to predict whether a patient obtains a locomotion mode of "walk" or "both" ( $c$ statistic increases from 0.80 to 0.88 and Max $R^{2}$ from 0.35 to 0.52 ). A higher lower extremity motor score (LEMS) on admission to the rehabilitation center and greater change in LEMS from admission to discharge, along with more time spent in PT balance training activities and more time that physical therapists spent in interdisciplinary conferences, are associated with greater likelihood of achieving a locomotion mode of "walk" or "both" by the time of rehabilitation discharge. Longer rehabilitation length of stay is associated with less likelihood of walking. The addition of rehabilitation center increases the c statistic to $0.90\left(\operatorname{Max} R^{2}=0.58\right.$; see Table 10$)$.

\section{Discussion}

The results of the current study demonstrate that time in specific PT activities was correlated with a variety of outcomes related to function and quality of life. As FIM outcomes were examined for groups of patients that were more homogeneous in terms of level and severity of injury, and therefore functional expectations and therapeutic need, PT treatment variables contributed more to the variation in outcomes of interest for these groups. Others have reported that examining the quantity (total hours) of PT services did not predict functional outcomes for patients with SCI and traumatic brain injuries and suggested that a more extensive list of detailed patient characteristics, as well as time in specific activities, may be more predictive. ${ }^{20}$ The increased ability of PT treatment variables to explain variation in outcomes for functionally homogeneous subgroups of patients, as compared to the total study sample that includes patients of all injury levels, supports the assertion that PT is not a one-size-fits-all approach. Physical therapists design treatment plans based on a number of patient-specific factors, including level and severity of injury, pre-morbid status, medical complications, and age. ${ }^{47}$ The current study demonstrates that injury grouping (based on both AIS and injury level) is a predictor of functional outcomes. This supports professional practice guidelines that state that therapists should use their evaluation skills and clinical judgment to help patients set realistic goals. Physical therapists then select appropriate PT treatments based on patients' functional abilities in order to meet these goals. ${ }^{47}$ For example, the functional expectations, mobility-related goals, and PT interventions would be very different for a patient admitted with a C4 AIS A injury than for one with a T8 AIS C injury.

Rehabilitation is an interactive process in which patient participation can greatly influence outcomes. The Pittsburgh Rehabilitation Participation Scale score was a significant predictor of all outcomes examined except whether patients reside at home at 1 year post-injury. The relationship between patient participation and discharge motor FIM scores has been reported previously in a general inpatient rehabilitation population. ${ }^{34}$ Good patient participation in rehabilitation may result in better outcomes for multiple reasons. It is possible that patients who participate more during PT sessions will be more attentive to instruction, harder working, and more receptive to feedback, thus getting more out of their rehabilitation experience. It may also be that patients who are more participatory are likely to have personality attributes, such as optimism, that may influence outcomes.

Treatment variables of clinical interest that were significant negative predictors of discharge motor FIM scores for the full sample include musculoskeletal treatments/modalities and ROM/stretching. Patients spending significant time in musculoskeletal treatments/ modalities may be doing so because of pain issues secondary to SCI or because of a co-morbid injury (such as an extremity fracture). Physical therapists may spend time treating a patient's musculoskeletal impairments so that they may tolerate a functional activity before working on increasing patient independence with the skill. Similarly, increased time may be spent in $\mathrm{ROM}$ /stretching activities if ROM limitations are preventing the patient from working on functional activities. For example, decreased excursion of the hamstrings or capsular tightness limiting shoulder extension could limit a patient's ability to participate in longsitting balance activities in preparation for more advanced skills such as transfers. 
Mobility-related outcomes for specific subsets of patients

\section{Patients with motor complete low tetraplegia $\left(\mathrm{C}_{5}-8\right)$}

A small subset of patients (78) had motor complete low tetraplegia and did not show signs of neurological improvement during rehabilitation as measured by their AIS classification and level of injury at admission and discharge. The large increase in the $R^{2}$ seen when PT treatments are added to patient characteristics for predicting the transfer component of the discharge motor FIM score is due largely to time spent working on manual wheelchair skills (smallest $P$ value and largest semi-partial Omega ${ }^{2}$ ). This finding is in contrast to motor control literature regarding specificity of training. However, many patients with C5-8 motor complete injuries use both power and manual wheelchairs during inpatient rehabilitation, and it is possible that more time in manual wheelchair mobility training will contribute to an increase in upper extremity muscular strength and endurance. These improvements in components of physical capacity may contribute to increased independence with transfers. The relationship between physical capacity improvements (as measured by upper extremity muscle strength and peak power output) and performance of a manual wheelchair circuit have been reported. ${ }^{48}$ In addition, individuals with chronic C6-7 tetraplegia who use manual wheelchairs have been reported to have better physical function (as measured by the Spinal Cord Independence Measure III and CHART: Mobility) than those who use power wheelchairs as their primary means of mobility. ${ }^{49}$

A positive association also was seen between total time spent on transfer training during rehabilitation and the transfer component of the motor FIM at 1 year post-injury. The transfer component is a composite of scores for three types of transfers (bed, chair, wheelchair; tub/shower and toilet); therefore, in the current study, total hours of transfer training, rather than the number of sessions practicing transfers to a specific surface, may be more predictive of this outcome. It is also important to note that the quantity of PT transfer training is not representative of the total hours of transfer training received by these patients during SCI rehabilitation, as teaching of these skills is shared with other disciplines, especially occupational therapy.

Another clinically interesting relationship for patients with motor complete tetraplegia is that time spent working on upright activities is inversely related to the transfer component of the motor FIM score at 1 year post-injury. Upright activities, such as the use of a tilt table or standing frame, aim to normalize patient blood pressure (BP) regulation. This is typically more impaired for patients with tetraplegia than those with paraplegia. ${ }^{24,50}$ Ongoing orthostatic hypotension may limit patient participation in transfer training during SCI rehabilitation, which could influence long-term transfer independence. Unstable BP also could make practicing functional activities dangerous for both the patient and therapist, which may limit therapist selection of transfer training as an appropriate activity. ${ }^{51}$ Patients may also continue to have orthostasis following discharge, requiring additional physical assistance to ensure safety during transfers.

Patients with motor complete paraplegia (T1-9) When predicting the motor FIM score at discharge from rehabilitation for the full analytic sample, the greatest amount of explained variance is due to patient characteristics; the strongest predictor is injury group (patients with AIS A, B, C tetraplegia/paraplegia have significantly lower scores as compared to patients with AIS $D)$. Given the strong explanatory power of the patient characteristics $\left(R^{2}=0.65\right)$ and such varied PT interventions provided to the total sample of patients with SCI, treatment variables only slightly increase the $R^{2}\left(R^{2}=\right.$ 0.77). However, when examining the same outcome for a group of patients who have similar injuries (motor complete T1-9), the amount of variation explained by patient characteristics alone is much smaller $\left(R^{2}=0.30\right)$ and the explanatory power of PT treatment variables is much greater $\left(R^{2}\right.$ increases to $0.64)$. The strongest patient variable for this subgroup is being male, which supports previous findings and may be related to gender differences in strength when performing functional activities. ${ }^{52}$

Obesity places an increased physical demand on upper extremity musculature and increased energy expenditure is required in order to mobilize additional body weight. The current study found obesity (BMI $\geq$ 30 ) to be associated with lower discharge motor FIM scores. Similarly, obese patients with motor complete paraplegia have lower motor FIM score gains during inpatient rehabilitation than their counterparts with normal body weight. ${ }^{9}$ Being married was associated with lower discharge motor FIM scores. Possibly due to dependence on a spouse to assist with functional activities, these patients may be under less constraint to perform skills independently.

Time in numerous PT treatment activities was found to be a significant predictor of the discharge motor FIM score for patients with motor complete T1-9 injuries. Therapeutic exercise documented as "endurance" incorporated both cardiovascular and muscular conditioning. ${ }^{24}$ Endurance exercise contributes to an 
increase in overall physical capacity, ${ }^{53,54}$ which may translate into improved ability to perform daily activities with more metabolic efficiency. If patients have greater energy reserves, they may be less likely to require physical assistance with self-care and mobility activities, which is a possible reason that endurance exercise is associated with increased motor FIM scores at discharge.

Use of a manual wheelchair is the primary means of locomotion for patients with motor complete paraplegia; therefore, manual wheelchair training is an integral component of SCI rehabilitation. The association of more time spent in manual wheelchair mobility with higher discharge motor FIM scores could be expected. The motor FIM includes scoring of the wheelchair skills propulsion and stair negotiation, and it is logical to expect that time practicing these skills during PT sessions would be associated with higher motor FIM scores. In addition, time spent practicing wheelchair skills may contribute to increased strength, power, and endurance of the upper extremities (components of physical capacity), which could contribute to overall functional independence. Studies have reported that practicing wheelchair skills, including pushing up an incline ${ }^{55}$ and curb negotiation, ${ }^{56}$ require great force generation of upper extremity musculature. Practicing additional advanced skills, such as uprighting a manual wheelchair from the floor after falling backward (with patient in chair), could also be expected to require great upper extremity power.

As previously discussed, patients with paraplegia are expected to become independent with all aspects of mobility. Therefore, more time dedicated to skills considered to be of a "lower" functional level, such as bed mobility, might be expected to be associated with lower discharge motor FIM scores. These skills may consume time that could be spent practicing more advanced skills, such as certain transfers or wheelchair skills. We also observed that more time spent in classes led by physical therapists, which, while important to increase a patient's knowledge of SCI and the promotion of lifelong health and wellness, was associated with lower discharge motor FIM scores. It is possible that additional classes were provided to patients who were unable to tolerate as much functional training. Lastly, time that physical therapists spend in assessment was also associated with lower discharge FIM scores. Normally, extensive formal assessment of a patient's strengths and impairments occurs at admission and discharge only. Formal assessment at times other than admission and discharge would indicate a change in patient status, such as the development of pain or musculoskeletal dysfunction, which could inhibit performance of functional activities included in the FIM. ${ }^{57}$

PT time spent in therapeutic exercise focused on balance may have been associated with lower motor FIM scores at 1 year post-injury for multiple reasons. Learning new balance strategies to compensate for impaired or absent motor and sensory innervation of the trunk and lower extremities is an integral component of inpatient rehabilitation for this subgroup of patients. ${ }^{58}$ Being able to control one's center of mass outside the base of support is a prerequisite for many mobility skills, including independent transfers between surfaces and performing wheelchair skills required for negotiating community settings. Decreased sitting balance is associated with lower motor FIM scores in patients with paraplegia, ${ }^{59}$ and more time spent on balance and not on the functional application of balance would indicate a patient is functioning at a lower level than the rest of the cohort. Furthermore, balance impairments can result in increased fear and risk of falling and decreased self-confidence, ${ }^{58,60}$ which could result in the need for physical assistance to perform the transfers.

\section{Patients with AIS D injuries}

Individuals with injuries classified as AIS D have the greatest preservation of strength below their injury level, particularly in their lower extremities. Admission LEMS and change in LEMS were the most predictive patient factors associated with having the primary locomotion mode of "walk" or "both (walk and wheelchair)" on the discharge motor FIM. The LEMS is a routinely available clinical measure that has been shown to be strongly correlated with factors related to walking ability. The LEMS has been used previously to distinguish between limited ambulators (those with slower average walking velocities, greater energy expenditure, and greater peak axial load through assistive devices) and community ambulators. ${ }^{61}$ The LEMS also was identified as the most predicative factor for delayed walking capacity, especially for individuals with tetraparesis. ${ }^{62}$ Similarly, a higher LEMS is related to a greater likelihood of walking, or transition from wheelchair use to walking, by 1 year post-injury. ${ }^{63}$ In contrast, it has also been reported that the LEMS alone was not a great predictor for walking improvements, which may be due to a lack of sensitivity in detecting strength gains needed for walking improvement. ${ }^{64}$

There are multiple reasons why more time spent in PT balance activities (standing or sitting, static or dynamic) may result in a greater likelihood of a patient's 
locomotor mode being "walk" or "both (walk and wheelchair)" at discharge from rehabilitation. Balance training may be selected by physical therapists in order to increase patient safety with ambulation and decrease the risk of falls. Balance training to promote safety while ambulating is warranted, as those who are ambulatory after traumatic SCI have been reported to have the highest rate of injuries, a portion of them due to falls. ${ }^{65,66}$ Since falls could potentially result in setbacks of neurological and functional recovery, clinical decision making is likely to lead therapists to select a wheelchair as the primary means of mobility for patients with poor balance who are at a high risk of falling. For patients with better balance, who are at less risk of falling, therapists are more likely to promote ambulation as a primary means of mobility. Balance and balance confidence have been shown to be predictors of walking quantity (as measured by daily stepping) ${ }^{67}$ and balance also affects walking level and performance in patients with chronic SCI. ${ }^{68}$ Multiple studies have shown balance to be a requirement for successful ambulation, further supporting the importance of balance training. ${ }^{69-71}$

Increased rehabilitation length of stay is linked to a decreased likelihood of achieving a locomotor mode of "walk" or "both (walk and chair)" at discharge. The majority of patients with AIS D injuries had cervical injuries, were older and were more likely to be injured in a fall; consistent with a diagnosis of central cord syndrome $(\mathrm{CCS}) .^{72}$ As compared to other patients in this subgroup, individuals with CCS may be affected by factors not captured in these analyses, including spasticity, trunk and arm muscle weakness, and neuropathic pain. These factors may have resulted in longer LOS and may also have impacted ambulation status. ${ }^{72}$

While most of the discussion has focused on the contribution of patient and treatment characteristics in predicting outcomes, the impact of rehabilitation center should also be mentioned. Rehabilitation center was incorporated as the third step in regression models to quantify the additional variation (beyond patient and treatment variables) explained by center location. For nearly all of the outcomes examined for the analytic dataset, the addition of rehabilitation center added little to no additional explanation of variance $(0.01$ or less). The only exceptions were residential location at 1 year post-injury ( $c$ statistic increase by 0.05 ) for the full sample, and discharge motor FIM for the subgroups of T1-9 and AIS D and motor FIM at 1 year for the AIS D subgroup ( $R^{2}$ increase by $0.05-0.07$ ). These small (or absent) increases in explanatory power when rehabilitation center was added to the stepwise regression modeling process after patient and treatment variables probably indicate that most of the variation in center practices was captured in the type and duration of specific treatments provided. Despite the robust list of patient characteristics, PT treatments and center variables included in the models, there may be additional factors related to these outcomes that were not captured in this study but may account for the unexplained variation.

The findings of this study have implications for PT treatment planning, as well as future research studies. It is important to remember that the PBE research approach, being based on clinical practice, is not focused on just one intervention, but rather the combination of interventions as part of a comprehensive rehabilitation program. Clinicians may consider the specific PT interventions that were positively associated with outcomes of interest when choosing interventions to emphasize with their patients (i.e. additional time in manual wheelchair mobility for patients with motor complete low tetraplegia and paraplegia). However, it is important to remember that associations should not be interpreted as causation. This study may help refine the scope of clinical trials looking at more efficacious treatments for patients with SCI.

\section{Limitations}

Although the findings reported here are compelling, there are limitations that warrant discussion. Use of the FIM has several advantages in rehabilitation research, including its widespread utilization in rehabilitation units in the United States, the standardization of administration through a certification process for clinicians using the measure, and the ability to compare patient admission and discharge status on specific tasks. The FIM, however, has been criticized on multiple grounds, including limitations in measuring change, ${ }^{73-75}$ the lack of specificity for $\mathrm{SCI},{ }^{7,76}$ significant ceiling and floor effects, ${ }^{77}$ and susceptibility to bias. ${ }^{78}$ In addition, there are limitations to using the FIM mode of locomotion at discharge as an ambulation outcome. The FIM, designed to strictly measure burden of care, does not capture progress in transitioning between types of assistive devices or bracing utilized during ambulation, which are likely to be meaningful changes to patients. Also, both modes of locomotion are assessed only up to 150 feet, which does not show improvements in endurance that would be important for a patient's community locomotion. Other outcome measures exist that may be better suited for patients with SCI, including the Quadriplegic Index of Function (QIF), ${ }^{74,75}$ the Walking Index for Spinal 
Cord Injury (WISCI), ${ }^{79}$ and the Spinal Cord Independence Measure version III (SCIM III). ${ }^{74}$ Furthermore, Middleton et al. ${ }^{80}$ suggested five additional items (5-AML) to be used in conjunction with the FIM to better identify functional progress with individuals with paraplegia and tetraplegia who use a wheelchair as their primary means of mobility. However, these measures are not used consistently in rehabilitation centers. Therefore, the FIM was deemed the most appropriate and practical outcome measure available; however, caution must be used when interpreting FIM scores.

The grouping of patients into the neurological injury subgroups was based on knowledge about key functional differences between categories of injury. Patients with low tetraplegia (C5-C8) typically have functional use of their upper extremities; however; there are large variations in functional abilities, just by virtue of the level of injury. While the specific level of injury was treated as a predictor variable in the $\mathrm{C} 5-8$ subgroup analysis, this may not have been fully adequate to control for patient variation in muscle innervation. ${ }^{81}$

Clinicians developed the PT taxonomy approximately 1 year prior to the start of data collection and each rehabilitation facility continued program changes, independent of this study. It is possible that some of these changes in practice could not be captured. For example, one site added activity-based treatment opportunities (functional electrical stimulation cycling and functional grasping groups, whole-body vibration, balance groups, etc.), which may have resulted in subcategorization of therapy activities not included in the SCIRehab documentation tools.

In addition to potential changes in practice, there is also the possibility of changes in documentation over time in this study. Clinicians documented therapy activities on a PDA, which was a new documentation process. Furthermore, the added documentation for the study required additional time for the clinicians at the end of their treatment sessions or the end of the workday. Although data collection were standardized across sites with periodic reliability assessments and efforts were made to ensure a complete dataset, ${ }^{25,29}$ it is possible that not all treatment sessions delivered are represented in the dataset. There also remains the possibility that there was also some variability in the way clinicians documented a given treatment activity.

\section{Conclusion}

Selection and quantity of PT interventions during inpatient SCI rehabilitation vary based on level and severity of injury and other issues that affect functioning needs.
Time spent in specific PT activities is associated with a wide variety of outcomes related to function and quality of life at discharge and at 1 year post-injury. Patient participation during PT sessions was a significant predictor of a majority of outcomes in this study. The influence of PT activities on functional outcomes becomes clearer when they are examined in subgroups of patients with similar neurological status and outcomes that are specifically relevant to the subgroup. Our findings have implications for treatment planning and therapists may begin to incorporate these associations into the selection of treatment activities. These findings may also serve to guide future clinical trials to show causation between PT interventions and outcomes. Overall, these findings may contribute to helping individuals maximize their functional potential and quality of life following SCI.

\section{Acknowledgements}

The contents of this paper were developed under grants from the National Institute on Disability and Rehabilitation Research, Office of Rehabilitative Services, U.S. Department of Education, to Craig Hospital (grant numbers H133A060103 and H133N060005), the MedStar National Rehabilitation Hospital (grant number H133N060028), Rehabilitation Institute of Chicago (grant number H133N060014), the Mount Sinai School of Medicine (grant number H133N060027), and to Shepherd Center (grant number H133N060009). The opinions contained in this publication are those of the grantees and do not necessarily reflect those of the US Department of Education.

\section{References}

1 Kirshblum SC, Burns SP, Biering-Sorensen F, Donovan W, Graves $\mathrm{DE}$, Jha $\mathrm{A}$, et al. International standards for neurological classification of spinal cord injury (Rev. 2011). J Spinal Cord Med 2011; 34(6):535-46.

2 Berney S, Bragge P, Granger C, Opdam H, Denehy L. The acute respiratory management of cervical spinal cord injury in the first 6 weeks after injury: a systematic review. Spinal Cord 2011;49(1): 17-29.

3 Postma K, Bussmann J, Haisma J, Bergen M, Stam H. Predicting respiratory infection one year after inpatient rehabilitation with pulmonary function measured at discharge in persons with spinal cord injury. J Rehabil Med 2009;41(9):729-33.

4 Krause J, Saunders L. Health, secondary conditions, and life expectancy after spinal cord injury. Arch Phys Med Rehabil 2011;92(11):1770-5.

5 Kroll T, Neri M, Ho P. Secondary conditions in spinal cord injury: results from a prospective survey. Disabil Rehabil 2007;29(15): 1229-37.

6 Paralyzed Veterans of America. Consortium for Spinal Cord Medicine Clinical Practice Guidelines. 1999. Available from http://www.pva.org/site/PageServer?pagename=research_consort (Accessed 2012 April 2).

7 Ota T, Akaboshi K, Nagata M, Sonoda S, Domen K, Seki M, et al. Functional assessment of patients with spinal cord injury: measured by the motor score and the functional independence measure. Spinal Cord. 1996;34(9):531-5. 
8 Seel R, Huang M, Cifu D, Kolakowsky-Hayner S, McKinley W. Age-related differences in length of stays, hospitalization costs, and outcomes for an injury-matched sample of adults with paraplegia. J Spinal Cord Med 2001;24(4):241-50.

9 Stenson K, Deutsch A, Heinemann A, Chen D. Obesity and inpatient rehabilitation outcomes for patients with traumatic spinal cord injury. Arch Phys Med Rehabil 2011;92(3):384-90.

10 DeVivo M. Discharge disposition from model spinal cord injury care system rehabilitation programs. Arch Phys Med Rehabil 1999;80(7):785-90.

11 Gulati A, Yeo C, Cooney A, McLean A, Fraser M, Allan D. Functional outcome and discharge destination in elderly patients with spinal cord injuries. Spinal Cord 2011;49(2):215-8.

12 Forchheimer M, Kalpakjian C. Gender differences in community integration after spinal cord injury. Top Spinal Cord Inj Rehabil 2004;10(2):163-74.

13 Tomassen P, Post M, van Asbeck F. Return to work after spinal cord injury. Spinal Cord 2000;38(1):51-5.

14 Charlifue S, Apple D, Burns S, Chen D, Cuthbert J, Donovan W, et al. Mechanical ventilation, health, and quality of life following spinal cord injury. Arch Phys Med Rehabil 2011;92(3):457-63

15 Jaglal S, Munce S, Guilcher S, Couris C, Fung K, Craven B, et al. Health system factors associated with rehospitalizations after traumatic spinal cord injury: a population-based study. Spinal Cord 2009;47:604-9

16 Chen Y, Cao Y, Allen V, Richards J. Weight matters: physical and psychosocial well being of persons with spinal cord injury in relation to body mass index. Arch Phys Med Rehabil 2011;92(3): 391-8.

17 Cardenas DD, Hoffman JM, Kirshblum S, McKinley W. Etiology and incidence of rehospitalization after traumatic spinal cord injury: a multicenter analysis. Arch Phys Med Rehabil 2004; 85(11): 1757-63.

18 Horn S, Gassaway J. Practice based evidence: incorporating clinical heterogeneity and patient-reported outcomes for comparative effectiveness research. Med Care 2010;48(6):17-22.

19 Whiteneck G, Gassaway J, Dijkers M, Charlifue S, Backus D, Chen $\mathrm{D}$, et al. Inpatient treatment time across disciplines in spinal cord injury rehabilitation. J Spinal Cord Med 2011;34(11): 133-48.

20 Heinemann A, Hamilton B, Linacre J, Wright B, Granger C. Functional status and therapeutic intensity during inpatient rehabilitation. Am J Phys Med Rehabil 1995;74(4):315-26.

21 van Langeveld S, Post M, van Asbeck F, Postma K, Leenders J, Pons K. Feasibility of a classification system for physical therapy, occupational therapy and sports therapy interventions for mobility and self-care in spinal cord injury rehabilitation. Arch Phys Med Rehabil 2008;89(8):1454-9.

22 van Langeveld S, Post M, van Asbeck F, Postma K, ten Dam D, Pons K. Development of a classification of physical therapy, occupational therapy and sports therapy interventions to document mobility and self-care in spinal cord injury rehabilitation. J Neurol Phys Ther 2008;32(1):2-7.

$23 \mathrm{Qu} \mathrm{H}$, Shewchuk R, Chen Y, Richards J. Evaluating the quality of acute rehabilitation care for patients with spinal cord injury: an extended Donabedian model. Qual Manag Health Care 2010; 19(1):47-61.

24 Natale A, Taylor S, LaBarbera J, Mumma S, Bensimon L, McDowell S, et al. SCIRehab: the physical therapy taxonomy. J Spinal Cord Med 2009;32(3):270-82.

25 Gassaway J, Whiteneck G, Dijkers M. Clinical taxonomy development and application in spinal cord injury research: the SCIRehab Project. J Spinal Cord Med 2009;32(3):260-9.

26 Taylor-Schroeder S, LaBarbera J, McDowell S, Zanca J, Natale A, Mumma S, et al. Physical therapy treatment time during inpatient spinal cord injury rehabilitation. J Spinal Cord Med 2011;34(2): $149-61$.

27 Whiteneck G, Gassaway J, Dijkers M, Heinemann A, Kreider SED. Relationship of patient characteristics and rehabilitation services to outcome following spinal cord injury. J Spinal Cord Med 2012;35(6):484-502.

28 Horn S, Gassaway J. Practice-based evidence study design for comparative effectiveness research. Med Care 2007;45(10 Suppl 2): S50-7.
29 Whiteneck G, Gassaway J, Dijkers M, Jha A. New approach to study the contents and outcomes of spinal cord injury rehabilitation: the SCIRehab Project. J Spinal Cord Med 2009; 32(3):251-9.

30 Fiedler R, Granger C. Functional independence measure: a measurement of disability and medical rehabilitation. In: Chino $\mathrm{N}$, Melvin J, (eds.) Functional evaluation of stroke patients. Tokyo: Springer-Verlag; 1996. p. 75-92.

31 Averill R, McGuire T, Manning B, Fowler D, Horn S, Dickson P, et al. A study of the relationship between severity of illness and hospital cost in New Jersey hospitals. Health Serv Res 1992;27(5): 587-617.

32 Horn S, Sharkey P, Buckle J, Backofen J, Averill R, Horn R. The relationship between severity of illness and hospital length of stay and mortality. Med Care 1991;29(4):305-17.

33 Horn S. Clinical practice improvement: a new methodology for outcomes research. Nutrition 1996;12(5):384-5.

34 Lenze E, Munin M, Quear T, Dew M, Rogers J, Begley A, et al. The Pittsburgh rehabilitation participation scale: reliability and validity of a clinician-rated measure of participation in acute rehabilitation. Arch Phys Med Rehabil 2004;85(3):380-4.

35 National Spinal Cord Injury Statistical Center. Data collection syllabus for the national spinal cord injury database: 2006-2011 project period. Birmingham, AL: University of Alabama; 2011.

36 Whiteneck G, Brooks C, Charlifue S, Gerhart K, Mellick D, Overholser D, et al. (eds.) Guide for use of CHART: Craig handicap assessment and reporting technique. Englewood, CO: Craig Hospital; 1992.

37 Hall J, Dijkers M, Whiteneck G, Brooks C, Krause J. The Craig handicap assessment and reporting technique (CHART): metric properties and scoring. Top Spinal Cord Inj Rehabil 1998:4(1):16-30.

38 Mellick D, Walker N, Brooks C, Whiteneck G. Incorporating the cognitive independence domain into CHART. J Rehabil Outcome Measure 1999;3(3):12-21.

39 Diener E, Emmons R, Larsen J, Griffin S. The satisfaction with life scale. J Pers Assess 1985;49(1):71-5.

40 Spitzer R, Kroenke K, Williams J. Validation and utility of a selfreport version of PRIME-MD: the PHQ primary care study. Primary care evaluation of mental disorders. Patient health questionnaire. JAMA 1999;282(18):1737-44.

41 Harrop J, Naroji A, Maltenfort M, Ratliff J, Tjoumakaris S, Frank $\mathrm{B}$, et al. Neurologic improvement after thoracic, thoracolumbar and lumbar spinal cord (conus medullaris) injuries. Spine 2011; 36(1):21-5.

42 Kay E, Deutsch A, Wuermser L. Predicting walking at discharge from inpatient rehabilitation after a traumatic spinal cord injury. Arch Phys Med Rehabil 2007;88(6):745-50.

43 Kutner M, Neter J, Nachtsheim C, Li W. Applied linear statistical models. 5th ed. New York, NY: Irwin Professional Pub; 2004.

44 Hosmer D, Lemeshow S. Applied logistic regression. 2nd ed. New York, NY: John Wiley \& Sons; 2000.

45 Nagelkerke N. A note on a general definition of the coefficient of determination. Biometrika 1991;78(3):691-2.

46 Nizam A, Kleinbaum D, Muller K, Kupper L. Applied regression analysis and other multivariable methods. 3rd ed. Pacific Grove CA: Duxbury Pr; 1998.

47 American Physical Therapy Association. Guide to physical therapist practice. Alexandria, VA: APTA; 2001.

48 Kilkens O, Dallmeijer A, Nene A, Post M, van der Woude L. The longitudinal relation between physical capacity and wheelchair skill performance during inpatient rehabilitation of people with spinal cord injury. Arch Phys Med Rehabil 2005;86(8):1575-81.

49 Hastings J, Robins H, Griffiths Y, Hamilton C. The differences in self-esteem, function, and participation between adults with low cervical motor tetraplegia who use power or manual wheelchairs. Arch Phys Med Rehabil 2011;92(11):1875-8.

50 Rosado-Rivera D, Radulovic M, Handrakis J, Cirnigliaro C, Jensen A, Kirshblum S, et al. Comparison of 24-hour cardiovascular and autonomic function in paraplegia, tetraplegia, and control groups: implications for cardiovascular risk. J Spinal Cord Med 2011;34(4):395-403.

51 Illman A, Stiller K, Williams M. The prevalence of orthostatic hypotension during physiotherapy treatment in patients with an acute spinal cord injury. Spinal Cord 2000;38(12):741-7. 
52 Sipski M, Jackson A, Gomez-Marin O, Estores I, Stein A. Effects of gender on neurologic and functional recovery after spinal cord injury. Arch Phys Med Rehabil 2004;85(11):1826-36.

53 Janssen T, Dallmeijer A, Veeger D, van der Woude L. Normative values and determinants of physical capacity in individuals with spinal cord injury. J Rehab Res Dev 2002;39(1):29-39.

54 Haisma J, van der Woude L, Stam H, Bergen M, Sluis T, Bussmann J. Physical capacity in wheelchair-dependent persons with a spinal cord injury: a critical review of the literature. Spinal Cord 2006;44(11):642-52.

55 Sabick M, Kotajarvi B, An K. A new method to quantify demand on the upper extremity during manual wheelchair propulsion. Arch Phys Med Rehabil 2004;85(7):1151-9.

56 Van Drongelen S, van der Woude L, Janssen T, Angenot E, Chadwick E, Veeger D. Mechanical load on the upper extremity during wheelchair activities. Arch Phys Med Rehabil 2005;86(6): 1214-20.

57 Forchheimer M, Richards J, Chiodo A, Bryce T, Dyson-Hudson T. Cut point determination in the measurement of pain and its relationship to psychosocial and functional measures after traumatic spinal cord injury: a retrospective model spinal cord injury system analysis. Arch Phys Med Rehabil 2011;92(3): 419-24.

58 Betker A, Desai A, Nett C, Kapadia N, Szturm T. Game-based exercises for dynamic short-sitting balance rehabilitation of people with chronic spinal cord and traumatic brain injuries. Phys Ther 2007;87(10):1389-98.

59 Jørgensen V, Elfving B, Opheim A. Assessment of unsupported sitting in patients with spinal cord injury. Spinal Cord 2011; 49(7):838-43.

60 Douglas J. Wheelchair exercises for fitness and confidence. Diabetes Self Manag 2005;22(1):47-48, 51-53, 55.

61 Waters R, Adkins R, Yakura J, Vigil D. Prediction of ambulatory performance based on motor scores derived from standards of the American Spinal Injury Association. Arch Phys Med Rehabil 1994;75(7):756-60.

62 Zörner B, Blanckenhorn W, Dietz V, Curt A. Clinical algorithm for improved prediction of ambulation and patient stratification after incomplete spinal cord injury. J Neurotrauma 2010;27(1): 241-52.

63 Riggins M, Kankipati P, Oyster M, Cooper R, Boninger M. The relationship between quality of life and change in mobility 1 year postinjury in individuals with spinal cord injury. Arch Phys Med Rehabil 2011;92(7):1027-33.

64 Field-Fote E, Roach K. Influence of a locomotor training approach on walking speed and distance in people with chronic spinal cord injury: a randomized clinical trial. Phys Ther 2011; 91(1):48-60.

65 Krause J. Factors associated with risk for subsequent injuries after traumatic spinal cord injury. Arch Phys Med Rehabil 2004;85: 1503-8.

66 Brotherton S, Krause J, Nietert P. Falls in individuals with incomplete spinal cord injury. Spinal Cord 2007;45(1):37-40.
67 Saraf P, Rafferty M, Moore J, Kahn J, Hendron K, Leech K, et al. Daily stepping in individuals with motor incomplete spinal cord injury. Phys Ther 2010;90(2):224-35.

68 Scivoletto G, Romanelli A, Mariotti A, Marinucci D, Tamburella F, Mammone A, et al. Clinical factors that affect walking level and performance in chronic spinal cord lesion patients. Spine 2008; 33(3):259-64.

69 Behrman A, Bowden M, Nair P. Neuroplasticity after spinal cord injury and training: an emerging paradigm shift in rehabilitation and walking recovery. Phys Ther 2006;86(10):1406-25.

70 Horak F, Macpherson J. Postural orientation and equilibrium. In: Rowell L, Shepherd J, (eds.) Handbook of physiology and exercise. Regulation and integration of multiple systems. Bethesda, MD: American Physiological Society; 1996. p. 255-92.

71 Fritz S, Merlo-Rains A, Rivers E, Peters D, Goodman A, Watson $\mathrm{E}$, et al. An intensive intervention for improving gait, balance and mobility with chronic incomplete spinal cord injury: a pilot study of activity tolerance and benefits. Arch Phys Med Rehabil 2011; 92(11):1776-84.

72 McKinley W, Santos K, Meade M, Brooke K. Incidence and outcomes of spinal cord injury clinical syndromes. J Spinal Cord Med 2007;30(3):215-24.

73 Keith R, Granger C, Hamilton B, Sherwin F. The functional independence measure: a new tool for rehabilitation. Adv Clin Rehabil 1987;1:6-18.

74 Anderson K, Aito S, Atkins M, Biering-Sørensen F, Charlifue S, Curt A. Functional recovery measures for spinal cord injury: an evidence-based review for clinical practice and research. J Spinal Cord Med 2008;31:133-44.

75 Marino F, Huan M, Knight P, Herbison G, Ditunno J, Segal M. Assessing self care status in quadriplegia comparision of the quadriplegia index of function (QIF) and the functional independence measure (FIM). Paraplegia 1993;31:225-33.

76 Menter R, Weitzenkamp D, Cooper D, Bingley J, Charlifue S, Whiteneck G. Bowel management outcomes in individuals with long-term spinal cord injuries. Spinal Cord 1997;35(9):608-12.

77 Middleton J, Truman G, Geraghty T. Neurological level effect on the discharge functional status of spinal cord injured persons after rehabilitation. Arch Phys Med Rehabil 1998;79(11):1428-32.

78 Menter RR, Whiteneck GG, Charlifue SW, Gerhart K, Solnick SJ, Brooks CA, et al. Impairment, disability, handicap and medical expenses of persons aging with spinal cord injury. Paraplegia 1991;29(9):613-9.

79 Jackson A, Carnel C, Ditunno J, Read M, Boninger M, Schmeler $\mathrm{M}$, et al. Outcome measures for gait and ambulation in the spinal cord injury population. J Spinal Cord Med 2008;31(5):487-99.

80 Middleton J, Harvey L, Batty J, Cameron I, Quirk R, Winstanley J. Five additional mobility and locomotor items to improve responsiveness of the FIM in wheelchair-dependent individuals with spinal cord injury. Spinal Cord 2006;44(8):495-504.

81 Fujiwara T, Hara Y, Akaboshi K, Chino N. Relationship between shoulder muscle strength and functional independence measure (FIM) score among C6 tetraplegics. Spinal Cord 1999;37:58-61. 